Document downloaded from:

http://hdl.handle.net/10251/83639

This paper must be cited as:

Liu, L.; Matsushita, T.; Concepción Heydorn, P.; Leyva Perez, A.; Corma Canós, A. (2016). Facile Synthesis of Surface-Clean Monodispersed CuOx Nanoparticles and Their Catalytic Properties for Oxidative Coupling of Alkynes. ACS Catalysis. 6(4):2211-2221. doi:10.1021/acscatal.5b02935

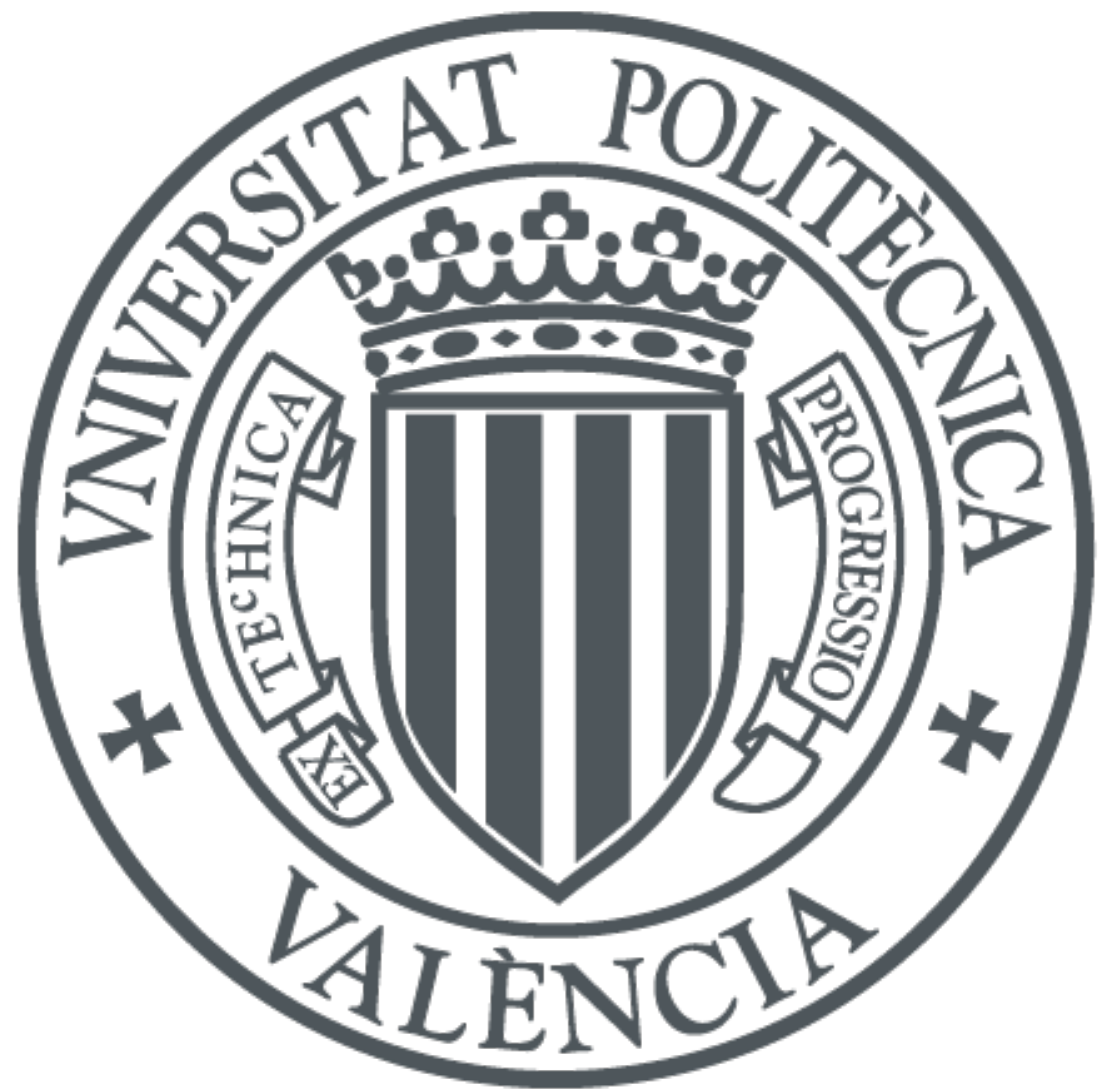

The final publication is available at

http://doi.org/10.1021/acscatal.5b02935

Copyright American Chemical Society

Additional Information 


\title{
Facile Synthesis of Surface-Clean Monodispersed CuOx Nanoparticles and Their Catalytic Properties for Oxidative Coupling of Alkynes.
}

Lichen Liu ${ }^{\mathrm{a}}$, Toshiyuki Matsushita ${ }^{\mathrm{b}}$, Patricia Concepcion ${ }^{\mathrm{a}}$, Leyva-Perez, Antonio and Avelino Corma $^{\mathrm{a} *}$

${ }^{a}$ Instituto de Tecnología Química, Universidad Politécnica de Valencia-Consejo Superior de Investigaciones Científicas (UPV-CSIC), Av. de los Naranjos s/n, 46022 Valencia, Spain

${ }^{b}$ Ube Industries, Ltd., 1978-5, Kogushi, Ube, Yamaguchi 755-8633, Japan

*Email: acorma@itq.upv.es

\begin{abstract}
We show a facile method to prepare surface-clean monodispersed small and stable $\mathrm{CuOx}$ nanoparticles with controllable average sizes from below $1 \mathrm{~nm}$ up to $\sim 5 \mathrm{~nm}$ without using bulk capping agent. Structural and surface characterizations show that the chemical states of $\mathrm{CuOx}$ nanoparticles and their interactions with $\mathrm{O}_{2}$ are dependent on the particle size. To show their relevance to catalysis, the well-defined monodispersed $\mathrm{CuOx}$ nanoparticles have been used for oxidative coupling of alkynes. While the generally used $\mathrm{CuCl}$ catalysts presents a reaction induction period and agglomerate into $\mathrm{CuOx}$ nanoparticles during the reaction, the induction period disappears when monodispersed $\mathrm{CuOx}$ nanoparticles $(\sim 2 \mathrm{~nm})$ were used as catalyst. Supported $\mathrm{CuOx}$ nanoparticles on $\mathrm{TiO}_{2}$ behave in the same way as monodispersed $\mathrm{CuOx}$ nanoparticles. Kinetic, spectroscopic and isotopic studies show that $\mathrm{O}_{2}$ activation is the rate-controlling step and the nature of the oxygen species formed on supported $\mathrm{CuOx}$ nanoparticles are dependent on the size of $\mathrm{CuOx}$ and determine the catalytic properties for oxidative coupling of alkynes.
\end{abstract}

Keywords: $\mathrm{CuOx}$ nanoparticles, size effect, oxidative coupling, terminal alkyne, $\mathrm{O}_{2}$ activation, unsymmetric 1,3-diynes 


\section{Introduction}

$\mathrm{CuO}_{\mathrm{x}}\left(\mathrm{Cu}_{2} \mathrm{O}\right.$ and $\left.\mathrm{CuO}\right)$ are important semiconductors that present wide applications in catalysis, gas sensing and photocatalysis. There is much work on controllable synthesis of $\mathrm{Cu}_{2} \mathrm{O}$ and $\mathrm{CuO}$ nanostructures and their applications in energy conversion, gas sensing and catalysis. ${ }^{1,2}$ However, most $\mathrm{CuO}_{\mathrm{x}}$ nanomaterials prepared in the literatures are larger than $5 \mathrm{~nm}$ with low surface areas. Since the catalytic properties of nanoparticles (NPs) are obviously related with their size, developing methodologies for synthesis of small $\mathrm{CuO}_{\mathrm{x}}$ NPs with diameter below $3 \mathrm{~nm}$ can be of much importance for catalytic applications.

In 2005, Yin et al. presented a method for the synthesis of uniform monodispersed $\mathrm{Cu}_{2} \mathrm{O}$ nanocrystals with sizes between 2 and $10 \mathrm{~nm},{ }^{3}$ in where oleic acid was used as capping agent and showed a negative effects on catalytic properties of $\mathrm{Cu}_{2} \mathrm{O}$ NPs. Meanwhile, high-temperature calcination (> $200{ }^{\circ} \mathrm{C}$ ) is usually required to remove the ligands with long carbon chains. ${ }^{4}$ Others have also prepared $\mathrm{CuOx}$ NPs but strongly interacting capping agents were also needed. ${ }^{5}$ So far, the preparation of small "surface clean" $\mathrm{CuO}_{\mathrm{x}} \mathrm{NPs}$ without bulky capping agent still remains a challenge.

Copper compounds (like $\mathrm{CuCl}, \mathrm{CuCl}_{2}, \mathrm{Cu}(\mathrm{acac})_{2}$ et al.) are widely used in organic synthesis as catalysts for oxidation reactions. ${ }^{6,7}$ There are many mechanistic studies on the role of $\mathrm{Cu}$ for oxidation reactions, and most of those works have been performed on the basis that mononuclear $\mathrm{Cu}$ or, in some cases, double $\mathrm{Cu}$ centers stabilized by ligands are thought to be active centers. ${ }^{8,9}$ Although there are some reports on the application of $\mathrm{Cu}$ NPs for aerobic oxidation reaction, the relationships between $\mathrm{Cu}$ compounds and Cu NPs are still not clear. In a recent work, we have seen that the $\mathrm{Cu}$ salts used initially as the catalyst for $\mathrm{C}-\mathrm{N}$ coupling reactions are not necessarily the active species, but they agglomerate during the reaction to form Cu clusters with a few atoms. ${ }^{10}$ This can be particularly relevant for oxidation reactions in where $\mathrm{O}_{2}$ activation may require $\mathrm{Cu}$ species with a certain number of $\mathrm{Cu}$ atoms. In the case of organic reactions that take place at low temperature, $\mathrm{O}_{2}$ dissociation or, in a more general way, $\mathrm{O}_{2}$ activation can become the rate-controlling step. To achieve the activation of the organic compounds and $\mathrm{O}_{2}$ simultaneously on isolated $\mathrm{Cu}$ cations seems like a difficult task, and in natural $\mathrm{Cu}$-containing enzymes, binuclear $\mathrm{Cu}$ centers are thought to be the active sites for activation of $\mathrm{O}_{2}{ }^{11,12}$ In the case of $\mathrm{Cu}$ NPs, the activation of $\mathrm{O}_{2}$ could be easier on small $\mathrm{Cu}$ 
NPs and the size as well as redox properties of $\mathrm{Cu}$ NPs, will be a key issue for establishing structure-activity relationships for Cu-catalyzed oxidation reactions. ${ }^{13}$

In the present work, we will show a facile method to prepare monodispersed small CuOx NPs with controllable average sizes from below $1 \mathrm{~nm}$ up to $\sim 5 \mathrm{~nm}$. By kinetic experiments, we will show how the size of the CuOx NPs controls the adsorption and activation of organic reactants and $\mathrm{O}_{2}$, as well as their facility to go into redox cycles. To show their relevance to catalysis, we have used these well-defined monodispersed CuOx NPs for oxidative coupling of alkynes. Then, by comparing with $\mathrm{CuCl}$ (the widely used catalyst for oxidative coupling of alkynes), it has been proved that a reaction induction period exists when $\mathrm{CuCl}$ is used as the starting catalyst. We have found that $\mathrm{CuCl}$ will evolve and agglomerate during the reaction. On the other hand, the reaction induction period disappears when monodispersed CuOx NPs ( 2 nm) were used as catalyst. After identifying the important role of CuOx NPs in oxidative coupling of alkynes, supported $\mathrm{CuOx}$ NPs on $\mathrm{TiO}_{2}$ were prepared as heterogeneous catalysts. The $\mathrm{CuOx} / \mathrm{TiO}_{2}$ catalysts show the same particle size effects, that with well-defined isolated nanoparticles. By means of kinetic, spectroscopic and isotopic studies, it has been found that $\mathrm{O}_{2}$ activation is the rate-controlling step and the nature of the oxygen species formed on supported $\mathrm{CuOx}$ NPs are dependent on the size of CuOx NPs.

\section{Experiments}

\subsection{Synthesis of monodispersed CuOx NPs and supported CuOx NPs.}

The CuOx NPs with different sizes were prepared as following. $\mathrm{CuCl}$ powder was added into 20 $\mathrm{mL}$ dimethylsulfoxide (DMSO). The suspension was heated to $90{ }^{\circ} \mathrm{C}$ under stirring. The $\mathrm{CuCl}$ powder became dissolved into DMSO when the suspension was kept at $90{ }^{\circ} \mathrm{C}$ for 20 minutes, leading to formation of a homogeneous solution and the size of CuOx NPs was modulated through the amount of $\mathrm{CuCl}$ in the solution. Samples will be labeled as $\mathrm{CuOx}-\mathrm{xx}$ with $\mathrm{xx}$ corresponding to the average particle size determined from TEM images.

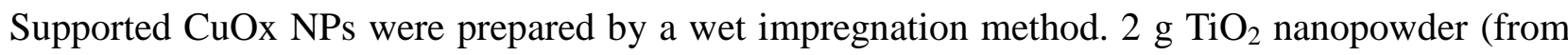
Aldrich, $21 \mathrm{~nm}$ average particle size), $30 \mathrm{~mL} \mathrm{H}_{2} \mathrm{O}$ and the desired $\mathrm{Cu}\left(\mathrm{CH}_{3} \mathrm{COO}\right)_{2}$ were mixed at room temperature and kept under stirring at room temperature for $1 \mathrm{~h}$. Then water is evaporated by heating in an oil bath at $120{ }^{\circ} \mathrm{C}$. Finally, $\mathrm{CuO}_{\mathrm{x}} / \mathrm{TiO}_{2}$ samples were obtained after calcination in $\mathrm{N}_{2}$ at 
$450{ }^{\circ} \mathrm{C}$ for $2 \mathrm{~h}$.

Metallic Cu clusters with 8-16 atoms were prepared by an electrochemical method according to reference. $^{14}$

\subsection{Characterizations}

The sizes of copper particles on supports were analyzed by TEM microscopy. Samples for electron microscopy studies were prepared by dropping the suspension of CuOx NPs directly onto holey-carbon coated Nickel grids. Studies have been performed in a JEOL 2100F microscope operating at $200 \mathrm{kV}$ both in transmission (TEM) and scanning-transmission modes (STEM). STEM images were obtained using a High Angle Annular Dark Field detector (HAADF), which allows Z-contrast imaging.

X-ray photoelectron spectra of the catalysts were carried out with a SPECS spectrometer equipped with a Phoibos 150MCD multichannel analyzer using MgKa (1253.6 eV) irradiation. The spectra were recorded at $-175^{\circ} \mathrm{C}$ and with an X-ray power of $50 \mathrm{~mW}$ in order to avoid photo-reduction of the copper species. The residual pressure in the analytical chamber was maintained below $10^{-9}$ mbar during data acquisition. For spectra acquisition, a drop of the monodispersed CuOx NP solution was deposited onto a Molibdenum sample holder and dried under $\mathrm{N}_{2}$ atmosphere inside the load lock of the XPS spectrometer. On the other hand, supported CuOx NP were prepared for analysis by depositing the powder onto a molybdenum sample holder. The binding energies of $\mathrm{Cu} 2 \mathrm{p}$ were corrected for surface charging by referencing them to the energy of C1s peak of adventitious carbon, set at $284.5 \mathrm{eV}$. Peak intensities have been calculated after nonlinear Shirley-type background subtraction and corrected by the transmission function of the spectrometer. The CasaXPS software has been used for spectra deconvolution.

Raman spectra were obtained with an “in via Reflex” Renishaw spectrometer, equipped with an Olympus microscope. The exciting wavelength was $785 \mathrm{~nm}$ from a Renishaw HPNIR laser with a power of ca. $15 \mathrm{~mW}$ on the sample. A micro quartz reactor located in a furnace has been used for the in situ Raman studies. The furnance is provided with a small hole in order to allow focalization on the sample with the laser spot. The reactor was positioned below the microscope objective, using a x50 long working distance objective (WD=10.6 nm). For the in situ studies the sample (10mgr) has 
been in situ activated in $\mathrm{N}_{2}$ flow for $1 \mathrm{~h}$ at $25{ }^{\circ} \mathrm{C}$. Then the sample has been exposed to a phenylacetylene $+\mathrm{O}_{2}$ flow at $90{ }^{\circ} \mathrm{C}$ for $1 \mathrm{~h}$. Afterwards the temperature was decrease to $25{ }^{\circ} \mathrm{C}$, and the gas flow switch to only $\mathrm{O}_{2}$. Temperature was increased from $25^{\circ}$ to $60^{\circ}$ and $90{ }^{\circ} \mathrm{C}$, collecting several spectra at each temperature.

FTIR spectra have been collected with a Nexus spectrometer from Thermo equipped with a DTGS detector $\left(4 \mathrm{~cm}^{-1}\right.$ resolution, 32 scans).The samples were pressed into self-supported pellets (ca. 10mg $\left.\mathrm{cm}^{-2}\right)$ and activated in vacuum $\left(10^{-4} \mathrm{mbar}\right)$ for $1 \mathrm{~h}$ at $25{ }^{\circ} \mathrm{C}$ prior to the IR studies. In the phenylacetylene adsorption studies, deuterated phenylacetylene ( $\mathrm{Ph}-\mathrm{C} \equiv \mathrm{C}-\mathrm{D})$ was adsorbed at $25^{\circ} \mathrm{C}$ at increasing dosing from 0.5 to 6.5 mbar, followed by further increasing the temperature to 60 and $90{ }^{\circ} \mathrm{C}$. Spectra were acquired at each temperature and after each dose. After $90{ }^{\circ} \mathrm{C}$, the sample was evacuated and the temperature lowered to $25{ }^{\circ} \mathrm{C}$ where 35 mbar $\mathrm{CO}$ was adsorbed for surface titration experiments. After $\mathrm{CO}$ evacuation the sample was exposed to $30 \mathrm{mbar} \mathrm{O}_{2}$ at $90{ }^{\circ} \mathrm{C}$ for $45 \mathrm{~min}$, followed by evacuation and further decreasing temperature to $25{ }^{\circ} \mathrm{C}$ were 35 mbar $\mathrm{CO}$ was again re-adsorbed for surface titration. In the in situ IR studies 6.5 mbar phenylacetylene was coadsorbed with $30 \mathrm{mbar} \mathrm{O}_{2}$ at $25^{\circ} \mathrm{C}$ and kept for $45 \mathrm{~min}$ at that temperature. Afterwards the temperature was raised to $90{ }^{\circ} \mathrm{C}$ for 45 min followed by sample evacuation at $10^{-4}$ mbar.

${ }^{18} \mathrm{O}$ Isotopic exchange of surface oxygen species followed by $\mathrm{H}_{2}$ titration, were carried out in a quartz flow reactor coupled to a quadrupole mass spectrometer (Omnistar, Balzers) for on-line monitoring of the exit gas composition. In each experiment, $100 \mathrm{mg}$ of sample diluted in $\mathrm{SiC}$ (1:1 ratio), has been activated in $\mathrm{N}_{2}$ flow for $1 \mathrm{~h}$ at $25{ }^{\circ} \mathrm{C}$. In the TPR of the ${ }^{18} \mathrm{O}_{2}$ oxidized samples, the sample, after activation, was exposed to a $20 \%{ }^{18} \mathrm{O}_{2}$ in $\mathrm{Ar}$ flow for $1 \mathrm{~h}$ at $90{ }^{\circ} \mathrm{C}$, followed by decreasing the temperature to $40{ }^{\circ} \mathrm{C}$ in an Ar flow and kept at that temperature for $20 \mathrm{~min}$. Afterwards the gas feed was switch to $10 \% \mathrm{H}_{2}$ in $\mathrm{Ar}$, and the temperature raised to $450{ }^{\circ} \mathrm{C}$, with a heating rate of $2{ }^{\circ} \mathrm{C} / \mathrm{min}$. In the TPR of the phenylacetylene $+{ }^{18} \mathrm{O}_{2}$ experiments the sample, after activation, was exposed to a phenylacetylen $+{ }^{18} \mathrm{O}_{2}$ flow at $90{ }^{\circ} \mathrm{C}$ for $1 \mathrm{~h}$, followed by decreasing the temperature to $40{ }^{\circ} \mathrm{C}$ in an Ar flow and kept at that temperature for $20 \mathrm{~min}$. Afterwards the gas feed was switch to $10 \% \mathrm{H}_{2}$ in $\mathrm{Ar}$, and the temperature raised to $450{ }^{\circ} \mathrm{C}$, with a heating rate of $2{ }^{\circ} \mathrm{C} / \mathrm{min}$.

Powder X-ray diffraction (XRD) was performed with a HTPhilips X'Pert MPD diffractometer equipped with a PW3050 goniometer using $\mathrm{CuK} \alpha$ radiation and a multisampling handler. 
Sample compositions of the DMSO solution of CuOx NPs were measured after acid-digestion by ICP-OES on a Varian 715-ES instrument.

The redox properties of copper particles on supports are evaluated by Temperature-programmed reduction (TPR). Micromeritics AutoChem 2910 catalyst characterization system with a thermal conductivity detector (TCD) was used. Prior to each experiment, about $100 \mathrm{mg}$ of sample was pretreated at room temperature in flowing He $(10 \mathrm{~mL} / \mathrm{min})$ for $20 \mathrm{~min}$. The sample was treated by heating from $25{ }^{\circ} \mathrm{C}$ to $600{ }^{\circ} \mathrm{C}$ at a rate of $5{ }^{\circ} \mathrm{C} \mathrm{min}^{-1}$ in a flow of $10 \mathrm{vol} . \% \mathrm{H}_{2}$ in Ar. The total gas flow rate was $50 \mathrm{~mL} / \mathrm{min}^{-1}$.

Fluorescence spectra were obtained with a LP S-220B (Photon Technology International) equipped with 75 W Xe lamp.

\subsection{Oxidative homo-coupling of alkynes.}

\subsubsection{Oxidative homo-coupling of alkynes by monodispersed CuOx NPs}

$110 \mu \mathrm{L}$ of alkyne (phenylacetylene) and $50 \mu \mathrm{L}$ nitrobenzene (as internal standard) and a given amount of copper catalyst ( $\mathrm{Cu}$ amount ranges from $0.5 \mathrm{~mol} \%$ to $10.0 \mathrm{~mol} \%)$ were added to $2 \mathrm{ml}$ of solvent (DMSO) in $10 \mathrm{~mL}$ round-bottom test tube with stirrer. The reaction flask was introduced in a preheated silicon oil bath at $90{ }^{\circ} \mathrm{C}$ and stirred at around $1000 \mathrm{rpm}$ under oxygen atmosphere (1 bar). Gas chromatography (Bruker with FID detector) was used for quantitative analysis of substrate and product.

\subsubsection{Oxidative homo-coupling of alkynes by supported CuOx NPs}

$55 \mu \mathrm{L}$ of alkyne (phenylacetylene) and $50 \mu \mathrm{L}$ nitrobenzene (as internal standard) and supported copper catalyst ( $\mathrm{Cu}$ amount ranges from $1.0 \mathrm{~mol} \%$ to $8.0 \mathrm{~mol} \%$ ) were added to $2 \mathrm{ml}$ of solvent (Toluene) in $10 \mathrm{~mL}$ round-bottom test tube with stirrer. The reaction flask was introduced in a preheated silicon oil bath at $90{ }^{\circ} \mathrm{C}$ and stirred at around $1000 \mathrm{rpm}$ under oxygen atmosphere (1 bar). Gas chromatography (Bruker with FID detector) was used for quantitative analysis of substrate and product.

\subsubsection{Oxidative hetero-coupling of alkynes by supported CuOx NPs}

$0.5 \mathrm{mmol}$ alkyne A, $0.25 \mathrm{mmol}$ alkyne B and $40 \mu \mathrm{L}$ dodecane (as internal standard) and supported copper catalyst $\left(\mathrm{CuOx} / \mathrm{TiO}_{2}-2.5 \%, 100 \mathrm{mg}\right)$ were added to $2 \mathrm{ml}$ of solvent (Toluene) in $10 \mathrm{~mL}$ 
round-bottom test tube with stirrer. The reaction flask was introduced in a preheated silicon oil bath at $100{ }^{\circ} \mathrm{C}$ and stirred at $1000 \mathrm{rpm}$ under oxygen atmosphere (5 bar). Gas chromatography (Bruker with FID detector) was used for quantitative analysis of substrate and product.

\section{Results and Discussions}
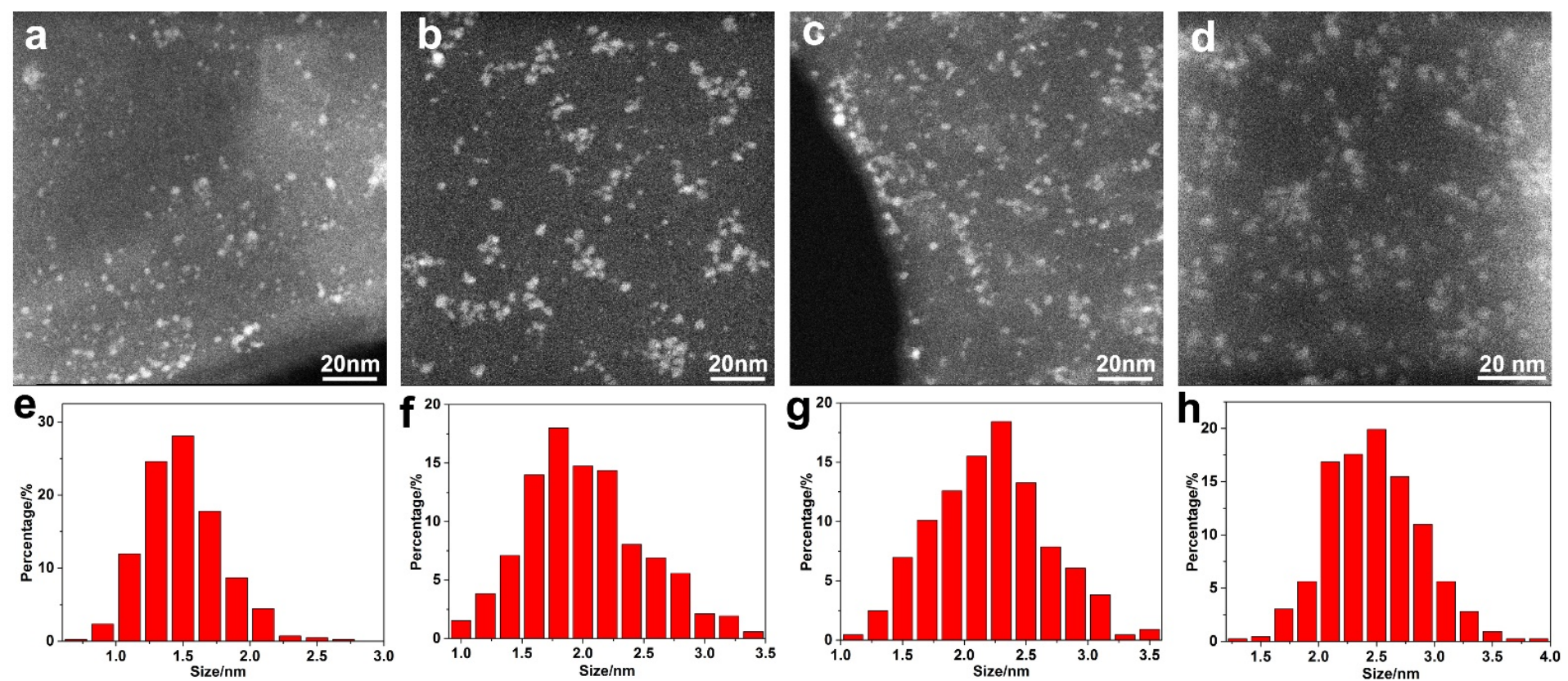

Figure 1. (a-d) STEM images of small $\mathrm{Cu}_{2} \mathrm{O}$ NPs with different sizes, a) CuOx-NC, b) $\mathrm{CuOx}-1.8$, c) CuOx-2.2 and d) CuOx-2.5. (e-h) size distributions of small CuOx NPs with different sizes, e) CuOx-NC, f) CuOx-1.8, g) CuOx-2.2 and h) CuOx-2.5.

\subsection{Synthesis and characterizations of monodispersed $\mathrm{CuOx}$ nanoparticles}

Monodispersed CuOx NPs could be easily synthesized by a thermal decomposition of $\mathrm{CuCl}$ in DMSO in presence of air. $\mathrm{CuCl}$ powder is not soluble in DMSO at room temperature. However, after heating the suspension at $90{ }^{\circ} \mathrm{C}$ for $20 \sim 30 \mathrm{~min}$ in air, a transparent solution was obtained. If CuCl-DMSO mixture is heated in $\mathrm{N}_{2}$ atmosphere, only small amount of $\mathrm{CuCl}$ can be dissolved in DMSO, suggesting that $\mathrm{O}_{2}$ participate in the thermal decomposition process (Figure S1). When the concentration of $\mathrm{Cu}$ is as low as $0.08 \mathrm{mg} / \mathrm{mL}, \mathrm{CuOx}$ NPs (denoted in this case as CuOx-NC) with sizes below $2 \mathrm{~nm}$ can be seen in the STEM images. According to the STEM images, the average size of those small CuOx NPs is about $1.5 \mathrm{~nm}$. However, it should be noticed that a large number of $\mathrm{Cu}$ clusters with size below $1 \mathrm{~nm}$ appear to exist but, due to the limitation of our STEM, they cannot be 
seen clearly. Indeed, photoemission studies show the presence of $\mathrm{Cu}$ clusters with 10-20 atoms (see the following discussion). So, the $\sim 1.5 \mathrm{~nm}$ average size given is certainly an over estimation of the average particle size. Increasing the concentration of $\mathrm{Cu}$ species leads to increasing the size of $\mathrm{CuOx}$ NPs. Then by controlling the concentration of $\mathrm{Cu}$, CuOx NPs with different sizes and narrow size distributions can be obtained ranging from clusters $(<1 \mathrm{~nm})$ up to $\sim 5 \mathrm{~nm}$, as shown in Figure 1 and Figure S2.

In a deeper structural characterization, the crystal lattice information of the CuOx NPs was acquired with high-resolution TEM. As shown in Figure S3, lattice fringes corresponding to $\mathrm{Cu}_{2} \mathrm{O}$ and $\mathrm{CuO}$ can be seen in the NPs of those four samples (From CuOx-NC to CuOx-2.5), suggesting that they should consist of both $\mathrm{Cu}(\mathrm{I})$ and $\mathrm{Cu}(\mathrm{II}) .{ }^{15,16}$ The elemental mapping results also confirm that those nanoparticles consist of both $\mathrm{Cu}$ and $\mathrm{O}$ (Figure S4a). Very small amounts of $\mathrm{Cl}$ have also been detected in several analyzed areas (Figure S4b). Compared with $\mathrm{Cu}$, the amount of $\mathrm{Cl}$ is much lower, suggesting that part of $\mathrm{Cl}$ is still residual in the DMSO solution after the thermal decomposition of $\mathrm{CuCl}$. In the HRTEM images of $\mathrm{CuOx}$ NPs with larger size (CuOx-4.5), most of the particles show lattice fringes of CuO (Figure S2). Thus, based on these HRTEM images, it is implied that the chemical states of $\mathrm{Cu}$ species may be different in different samples, depending on the particle size of $\mathrm{CuOx}$. In addition, the formation of $\mathrm{CuO}_{\mathrm{X}} \mathrm{NP}$ due to thermal decomposition of the $\mathrm{CuCl}$ precursor in air, has been supported by Raman spectroscopy where the absence of $\mathrm{Cu}-\mathrm{Cl}$ vibrations $\left(\sim 200 \mathrm{~cm}^{-1}\right)^{17}$ while the presence of Cu-O-Cu stretching modes $\left(\sim 434,493\right.$ and $\left.582 \mathrm{~cm}^{-1}\right)$ ${ }^{18,19}$ has been identified in all three samples (Figure $2 \mathrm{~d}$ ). 

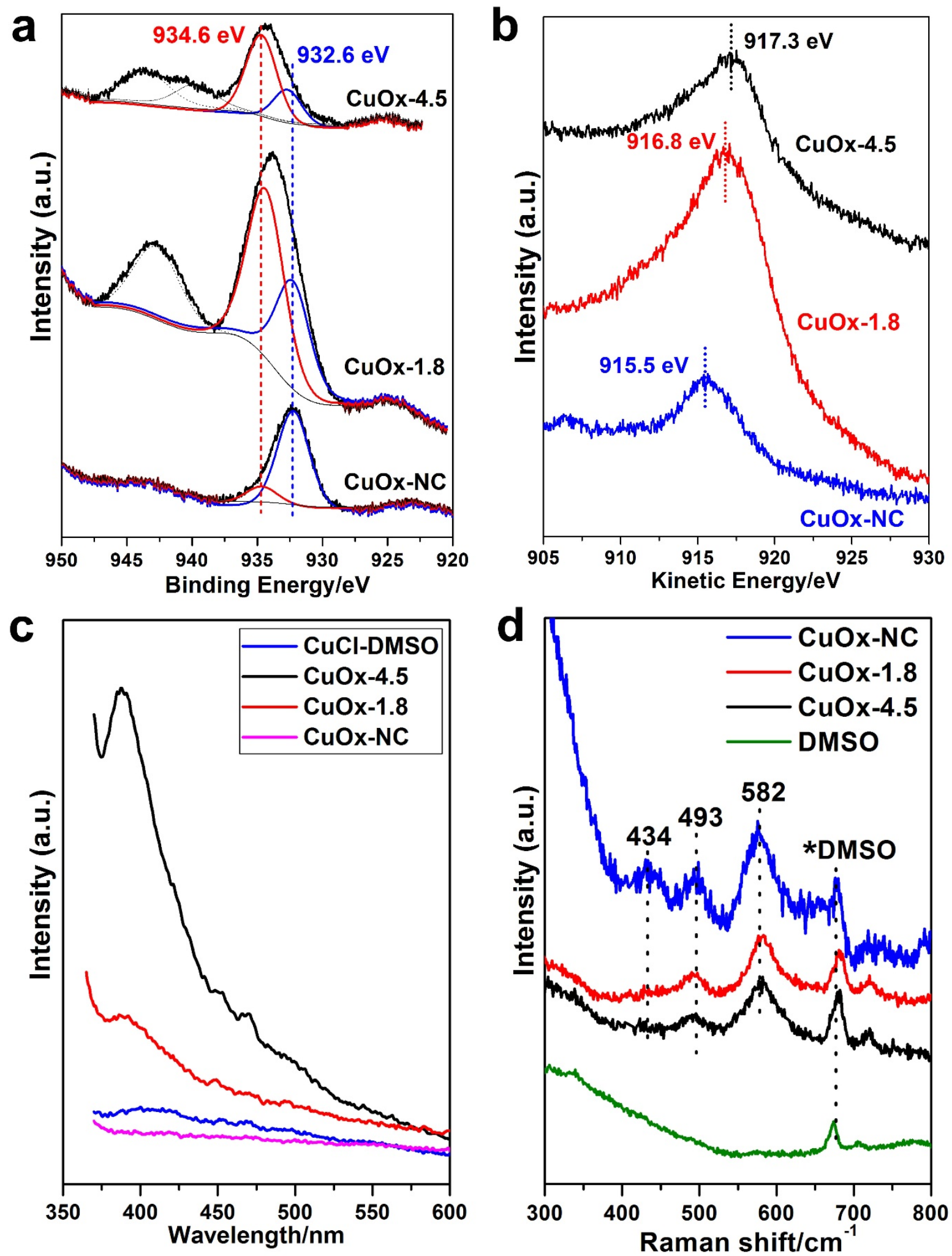

Figure 2. Spectroscopic characterizations of monodispersed $\mathrm{CuO}_{\mathrm{x}} \mathrm{NPs}$ of different sizes. $\mathrm{Cu} 2 \mathrm{p} 3 / 2$ XPS peak (a), CuL3VV Auger line (b) and fluorescence spectra at $350 \mathrm{~nm}$ excitation (c) and Raman spectra (d). 
Table 1 Fitting results of XPS spectra of $\mathrm{CuOx}-4.5$, CuOx-2.2 and $\mathrm{CuOx}-\mathrm{NC}$. a) $\mathrm{Cu}(\mathrm{II}) / \mathrm{Cu}(\mathrm{I})$ atomic ratio determined from XPS peak decovolution b) Satellite to main peak area ratio

\begin{tabular}{|c|c|c|}
\hline Sample & $\mathrm{Cu}(\mathrm{II})(934.6 \mathrm{eV}) / \mathrm{Cu}(\mathrm{I})(932.6 \mathrm{eV})^{\mathbf{a}}$ & $\mathbf{s}^{\mathbf{a}} \mathbf{m}^{\mathbf{b}}$ \\
\hline CuOx-NC & 0.16 & 0 \\
\hline CuOx-1.8 & 2.8 & 0.35 \\
\hline CuOx-4.5 & 5 & 0.66 \\
\hline
\end{tabular}

The $\mathrm{Cu} 2 \mathrm{p} 3 / 2$ X-ray photo-electron spectra (XPS) and Cu L3VV Auger spectra of the above samples are shown in Figure 2A and Figure 2B respectively. Two components at binding energy (BE) of $934.6 \mathrm{eV}$ and $932.6 \mathrm{eV}$ are observed in all samples but in different proportion. The higher BE of 934.6eV is due to $\mathrm{Cu}^{2+}$, while the lower $\mathrm{BE}$ of $932.6 \mathrm{eV}$ can be related either to $\mathrm{Cu}(\mathrm{I})$ or metallic $\mathrm{Cu}^{0} \cdot{ }^{20}$ Assignation to $\mathrm{Cu}^{0}$ can be excluded in samples $\mathrm{CuOx}-1.8$ and $\mathrm{CuOx}-4.5$ according to the peak position and band shape of the auger $\mathrm{Cu}$ L3VV peak. An anomalous Cu L3VV KE value is observed on sample CuOx-NC (915.5eV). Similar behavior, due to a small particle size effect, has already been observed by others authors, ${ }^{21}$ hindering true identification of copper oxidation state. Following the above assignment, it can be seen that from the values given in Table 1, the relative amount of $\mathrm{Cu}(\mathrm{II})$ to $\mathrm{Cu}(\mathrm{I})$ increases when increasing particle size (from clusters to $5 \mathrm{~nm}$ ), which fits with the increase in the shake-up satellite intensity. Moreover, the Cu L3VV peak position agrees with a higher contribution of $\mathrm{Cu}(\mathrm{II})$ in sample $\mathrm{CuOx}-4.5$ (Cu L3VV of $917.8 \mathrm{eV}$ ) and higher contribution of $\mathrm{Cu}(\mathrm{I})$ in sample CuOx-1.8 (Cu L3VV of $916.8 \mathrm{eV}) .{ }^{22} \mathrm{CuOx}-\mathrm{NC}$ is a mixture of clusters and nanoparticles, where the nanoparticles may exist in an oxidized form, according to their raman spectra, and mayoritary as $\mathrm{Cu}(\mathrm{I})$ due to the absence of satellite structure in the XPS spectra. $\mathrm{Cl}^{-}$ions have also been detected in the XPS analysis, which unavoidable comes from the thermal decomposition of the $\mathrm{CuCl}$ precursor in air. The existing form of $\mathrm{Cl}^{-}$is difficult to identify according to XPS BE data, while it may most probably remain dissolved in small amount of water present in the air or in the solvent.

The existence of $\mathrm{Cu}$ clusters in $\mathrm{CuOx}-\mathrm{NC}$ sample is also confirmed by fluorescence spectroscopy. As shown in Figure 2c, a strong emission peak can be found around $390 \mathrm{~nm}$, which corresponds to $\mathrm{Cu}$ clusters with 10 20 atoms. ${ }^{14}$ Pure $\mathrm{CuCl}$ solid shows no fluorescence emission, implying that $\mathrm{CuCl}$ is transformed into $\mathrm{CuOx}$ clusters in DMSO. The fluorescence intensity decreases dramatically when the particle size increases to $1.8 \mathrm{~nm}$, due to the high sensitivity of fluorescence with particle 
size. For CuOx-4.5 sample, almost no emission signal can be observed under those conditions. Accordingly with the characterization results observed up to now, it is possible to say that CuOx NPs with controllable and very narrow size distribution, ranging from clusters to $\sim 5 \mathrm{~nm}$ NPs, can be easily obtained by decomposing $\mathrm{CuCl}$ in DMSO in the presence of air, and the size of CuOx NPs can be tuned by changing the $\mathrm{Cu}$ concentration. Moreover, we can also say that the chemical state of $\mathrm{Cu}$ in the $\mathrm{CuOx}$ NPs changes with the particle size, increasing the $\mathrm{Cu}(\mathrm{II})$ to $\mathrm{Cu}(\mathrm{I})$ ratio when increasing the size of $\mathrm{CuOx}$ NPs.

\subsection{Catalytic properties of monodispersed $\mathrm{CuOx}$ NPs}

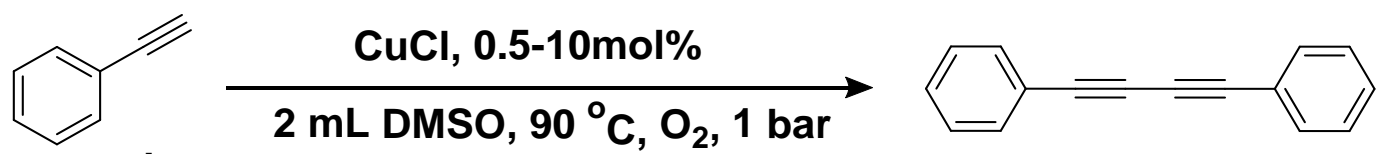

\section{$1.0 \mathrm{mmol}$}

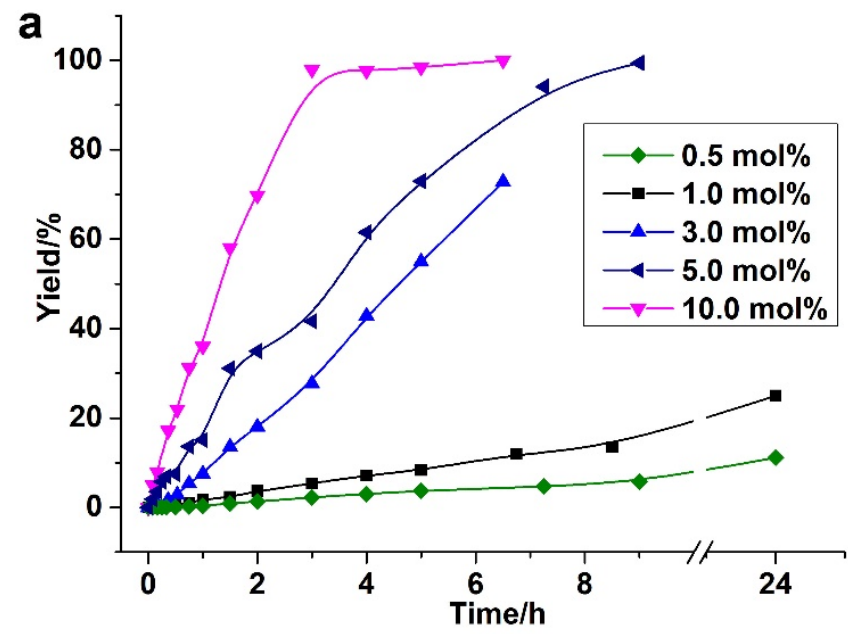

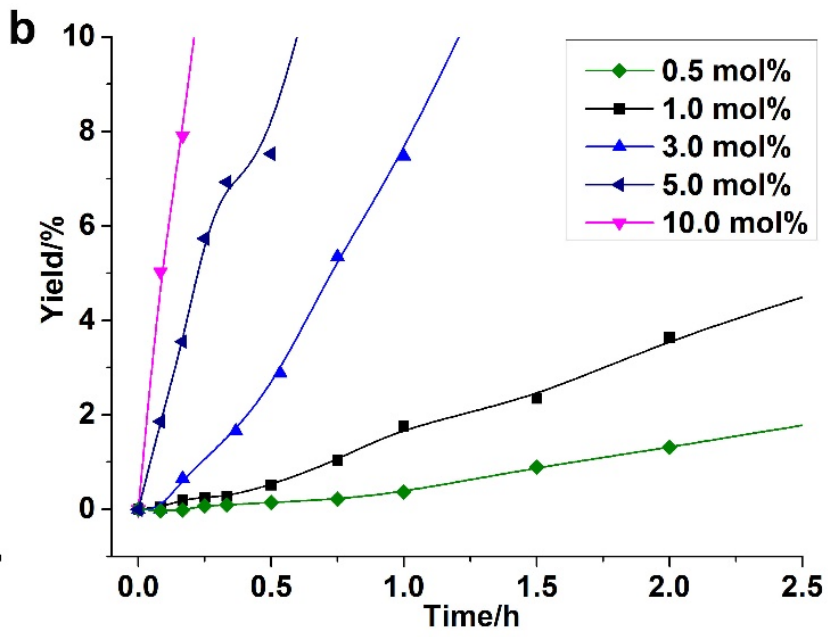

Figure 3. (a) The kinetic curves of CuCl-catalyzed homo-coupling of phenylacetylene using different amounts of $\mathrm{CuCl}$. (b) graphical zoom in the first $2.5 \mathrm{~h}$.

$\mathrm{Cu}$ compounds are widely used as superior catalysts for the oxidative homo-coupling of alkynes. $\mathrm{Cu}$ salts in pyridine media or in alcohol media can give high conversion for oxidative coupling of alkynes. ${ }^{23,24}$ It is not infrequent to find in the literatures that the reaction mechanism is thought to involve the mononuclear $\mathrm{Cu}$-alkyne complex. However, since $\mathrm{Cu}$ species can evolve during the reaction, one has to investigate the dynamic evolution of $\mathrm{Cu}$ species in the catalytic process to determine which are the catalytically active species. Therefore, we have used $\mathrm{CuCl}$ as the starting 
catalyst for performing the homo-coupling of phenylacetylene. Different amounts of $\mathrm{CuCl}$ were used as catalyst and the evolution of the reactants and catalyst were followed with time. As shown in Figure 3a and Figure 3b, it can be seen that when the amount of $\mathrm{CuCl}$ was below $5 \mathrm{~mol} \%$, the reaction goes through an induction period. During that time, conversion was not observed in the first 10-20 min. Furthermore, the induction period decreases when increasing the amount of CuCl. These kinetic results indicate that the initial $\mathrm{CuCl}$ may not be the real active catalyst, and some in situ transformation of $\mathrm{CuCl}$ may occur during reaction that give rise to the catalytically active $\mathrm{Cu}$ species.

In order to identify the evolution process of $\mathrm{CuCl}$ during the homo-coupling of the alkyne, the following experiment was carried out. A reaction mixture was prepared in one reactor with $10 \mathrm{~mol} \%$ $\mathrm{CuCl}$ and phenylacetylene. An aliquot of the reaction mixture was taken at different reaction times and introduced into a second reactor in where only the phenylacetylene was present. The amount of $\mathrm{Cu}$ in the second reactor was kept as $0.5 \mathrm{~mol} \%$. It should be remembered that when the oxidative coupling of phenylacetylene was catalyzed by $0.5 \mathrm{~mol} \%$ of $\mathrm{CuCl}$, an induction period of about $1 \mathrm{~h}$ was observed (see Figure 3). As shown in Figure S5, an induction period was observed in the second reaction when the aliquot from the first reactor was taken at time zero with the still no evolved original $\mathrm{CuCl}$. However, if the aliquot of the reaction mixture was taken from the first reactor after $0.5 \mathrm{~h}$, and it was added into the second reactor, the reactor started immediately without induction period (see Figure S5). The above experiment shows that, whatever the Cu active species for the oxidative coupling of alkynes are, they are not the $\mathrm{CuCl}$ but are formed in situ during the reaction. Therefore, we follow the evolution of the $\mathrm{Cu}$ species by taking samples at different reaction times. We choose the homo-coupling reaction catalyzed by $1.0 \mathrm{~mol} \%$ of $\mathrm{CuCl}$ and the $\mathrm{Cu}$ species in solution were analyzed by with STEM. STEM results (see Figure S6) show that the reaction starts when nanoparticles with size between 1 and $3 \mathrm{~nm}$ are present. Elemental mapping and high-resolution TEM images (see Figure S7) confirm that those nanoparticles should be CuOx NPs with lattice fringes corresponding to $\mathrm{Cu}_{2} \mathrm{O}$. The results imply that, the in situ transformation of $\mathrm{CuCl}$ into CuOx NPs may play an important role in the oxidative coupling of alkynes.

Similar phenomenon of the in situ transformation of $\mathrm{Cu}$ species during the oxidative coupling of alkynes have also been observed when other starting $\mathrm{Cu}$ compounds were used as the starting catalysts. For example, when $5.0 \mathrm{~mol} \%$ of $\mathrm{Cu}(\mathrm{Ac})_{2}$ was used as catalyst, an induction period of about 
2 h occurs (see Figure S8) and small CuOx NPs can also be observed with STEM after the induction period, as shown in Figure S9. For different $\mathrm{Cu}$ compounds, the induction period may be different, but when the reaction takes off, the in situ formed CuOx NPs show similar average sizes of $\sim 2 \mathrm{~nm}$. This common point implies that small CuOx NPs may play an important role in the oxidative homo-coupling of alkynes. Therefore, since CuOx NPs of controllable sizes can now be prepared, we performed the reaction using the separately prepared monodispersed CuOx NPs described before. Moreover, we have also used Cu clusters with 8-16 atoms prepared by electrochemical method (see experimental section) and their catalytic property was measured. Results given in Figure S10 clearly show that metal clusters give no activity for the oxidative homo-coupling of phenylacetylene. Moreover, the monodispersed $\mathrm{CuOx}$ samples (CuOx-NC and CuOx-2.2) are not only active but also give no induction period. Nevertheless, CuOx-2.2 show higher activity than CuOx-NC. Then, considering the presence of both small clusters and NPs in the CuOx-NC sample, we can speculate that only CuOx NPs are responsive for the catalytic activity.

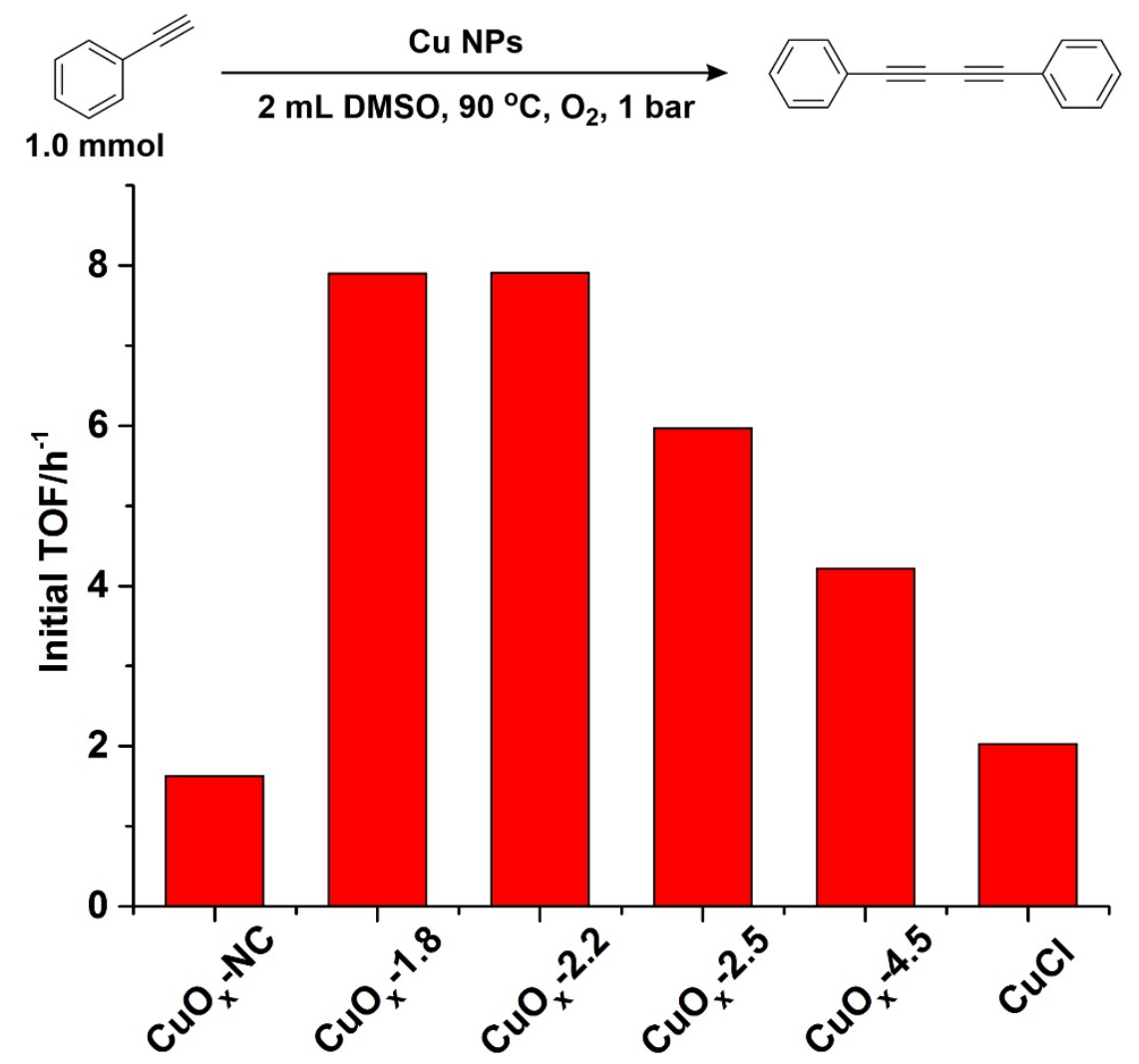

Figure 4. Kinetic studies of small CuOx NPs for homo-coupling of phenylacetylene. The initial TOF values of different $\mathrm{CuOx}$ NPs are calculated based on considering all the $\mathrm{Cu}$ species used in the reaction. 
The catalytic properties of the other $\mathrm{CuO}_{\mathrm{x}}$ NPs with different sizes have also been tested, and the results given in Figure 4 show a maximum activity for CuOx NPs around $\sim 2 \mathrm{~nm}$. Moreover, when the initial reaction rate is plotted versus the amount of CuOx-2.2 NPs added as catalyst (shown in Figure S11a and Figure S11b), a linear relationship is observed, indicating that the CuOx NPs are the active species for the oxidative coupling of phenylacetylene. The morphology of the CuOx-2.2 NPs was again checked after the homo-coupling reaction (after reaction time of $4 \mathrm{~h}$ ) and the size distribution is very similar to the fresh sample (see Figure S11c and Figure S11d). It should be remarked here that, the $\mathrm{CuOx}$ NPs with larger size (CuOx-4.5) show a short but visible induction period (about $10 \mathrm{~min}$ ) for the homo-coupling of phenylacetylene (see Figure S12). STEM and HRTEM images of CuOx-4.5 NPs after the homo-coupling reaction indicate that they have been transformed into $\mathrm{CuOx}$ NPs of around $2 \mathrm{~nm}$ during the reaction (see Figure S13). These results are again in line with the conclusion that $\mathrm{CuOx}$ NPs of $\sim 2 \mathrm{~nm}$ are the active species for the reaction.

\subsection{Preparation and characterizations of supported $\mathrm{CuOx}$ NPs}

From the work on isolated CuOx NPs, we have learnt that oxidative coupling of phenylacetylene is better catalyzed by $\mathrm{CuOx}$ NPs of $\sim 2 \mathrm{~nm}$. Thus, before studying why this occurs, we thought on the possibility to extend the knowledge acquired to prepare active supported $\mathrm{Cu}$ catalyst for the above reaction, by generating the adequate $\mathrm{CuOx}$ NPs on a support, to prepare an optimized and recyclable solid catalyst. Herein, a series of $\mathrm{CuOx} / \mathrm{TiO}_{2}$ samples (denoted as $\mathrm{CuOx} / \mathrm{TiO}_{2}-\mathrm{x} \%$, where $\mathrm{x}$ is the loading weight percentage of $\mathrm{Cu}$ ) were prepared through an impregnation method (see experimental section). Their XRD patterns are shown in Figure S14. Only diffraction peaks of anatase $\mathrm{TiO}_{2}$ and rutile $\mathrm{TiO}_{2}$ can be seen when the loading amount of $\mathrm{Cu}$ is lower than $5.0 \%$. For $\mathrm{CuOx} / \mathrm{TiO} \mathrm{S}_{2}$ samples with $10.0 \mathrm{wt} \%$ of $\mathrm{Cu}$, diffraction peaks corresponding to $\mathrm{CuO}$ can be observed, indicating the formation of big CuO NPs in this sample. As shown in Figure S15, the sizes of the different CuOx NPs supported on $\mathrm{TiO}_{2}$ were also investigated by STEM. According to the STEM images, their sizes range from below $1 \mathrm{~nm}$ to ca. $10 \mathrm{~nm}$. The elemental mapping results (shown in Figure S16 to Figure S20) also confirm the uniform dispersion of CuOx NPs on $\mathrm{TiO}_{2}$ support. The size distributions of CuOx NPs are also presented in Figure S21, indicating that the size of CuOx NPs increases when increasing the loading of $\mathrm{CuOx}$ on $\mathrm{TiO}_{2}$. 
The chemical states of $\mathrm{Cu}$ species in $\left(\mathrm{CuOx} / \mathrm{TiO}_{2}-2.5 \%\right.$ and $\left.\mathrm{CuOx} / \mathrm{TiO}_{2}-10 \%\right)$ were measured by XPS. From Figure S22, it can be deduced that both $\mathrm{Cu}^{+}$and $\mathrm{Cu}^{2+}$ are present in the two samples. Moreover, $\mathrm{CuOx} / \mathrm{TiO}_{2}-10 \%$ has a higher ratio of $\mathrm{Cu}^{2+} / \mathrm{Cu}^{+}$than $\mathrm{CuOx} / \mathrm{TiO}_{2}-2.5$. The reducibility of CuOx NPs with different sizes was also measured by temperature-programmed reduction (TPR). As shown in Figure S23, for $\mathrm{CuOx} / \mathrm{TiO}_{2}-0.25 \%$ the $\mathrm{H}_{2}$ consumption is very low compared to $\mathrm{CuOx} / \mathrm{TiO}_{2}-2.5 \%$ and to $\mathrm{CuOx} / \mathrm{TiO}_{2}-10 \%$ with lager particle sizes, implying the low redox reactivity of the subnanometric $\mathrm{CuOx}$ species in $\mathrm{CuOx} / \mathrm{TiO}_{2}-0.25 \%{ }^{13}$ For $\mathrm{CuOx} / \mathrm{TiO}_{2}-2.5 \%$, a big sharp peak ( $\boldsymbol{\alpha}$ peak) can be observed in the TPR profile, which is associated to the reduction of small CuOx NPs of around $2 \mathrm{~nm}$. In the case of $\mathrm{CuOx} / \mathrm{TiO}_{2}-10 \%$, two reduction peaks ( $\boldsymbol{\alpha}$ and $\boldsymbol{\beta}$ peak) can be observed, which can be ascribed to small CuOx NPs and big CuOx NPs, respectively. ${ }^{25}$ Considering that the $\mathrm{H}_{2}$ consumption corresponding to the $\boldsymbol{\beta}$ peak is much larger than that for the $\boldsymbol{\alpha}$ peak, it could be deduced that most $\mathrm{CuOx}$ NPs in $\mathrm{CuOx} / \mathrm{TiO}_{2}-10 \%$ are big $\mathrm{CuOx}$ NPs, which is consistent with the STEM characterization.
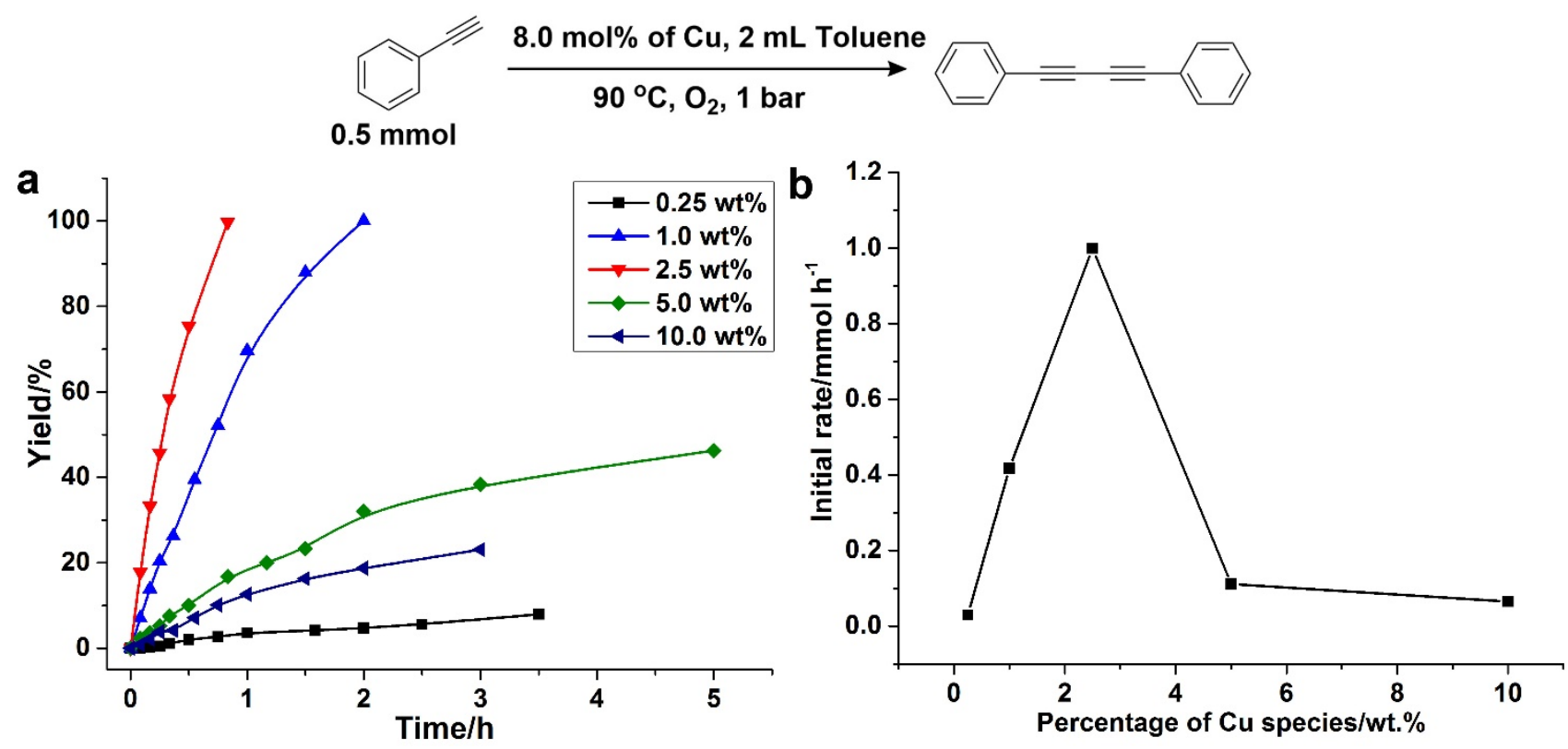

Figure 5 Kinetic studies(a) and the initial reaction rate (b) of $\mathrm{CuOx} / \mathrm{TiO}_{2}$ samples with different sizes of $\mathrm{CuOx}$ NPs in the homo-coupling reaction. The amount of $\mathrm{Cu}$ in all the tests are kept as $8.0 \mathrm{~mol} \%$.

\subsection{Catalytic properties of supported CuOx NPs}

The activities of $\mathrm{CuOx} / \mathrm{TiO}_{2}$ samples in the homo-coupling of phenylacetylene were measured under the experimental conditions described in the experimental section. As shown in Figure 5a, no 
induction period was observed and the activity of $\mathrm{CuOx} / \mathrm{TiO}_{2}$ samples is related with the sizes of the $\mathrm{CuOx}$ NPs formed on $\mathrm{TiO}_{2}$. $\mathrm{CuOx} / \mathrm{TiO}_{2}-2.5 \%$ sample with $\mathrm{CuOx}$ NPs around $2 \mathrm{~nm}$ gives the best activity compared with smaller or larger CuOx NPs (see Figure 5b), and the reaction can be finished in 40 min when $\mathrm{CuOx} / \mathrm{TiO}_{2}-2.5 \%$ is used as catalyst.

Combining the results on monodispersed and supported $\mathrm{CuOx}$ NPs, we can propose that the suitable size of $\mathrm{CuOx}$ NPs in $\mathrm{CuOx} / \mathrm{TiO}_{2}-2.5 \%$ should be the reason accounting for its high activity. Furthermore, the size-dependent catalytic properties of CuOx NPs follow a similar trend on both monodispersed and supported NPs.

The activity $\mathrm{CuOx} / \mathrm{TiO}_{2}-2.5 \%$ sample was also tested for homo-coupling of phenylacetylene using different amounts of $\mathrm{Cu}$ as the catalyst. As presented in Figure S24a, the reaction will boost once the catalyst is added into the reaction mixture, indicating that $\mathrm{CuOx} / \mathrm{TiO}_{2}-2.5 \%$ sample can catalyze the reaction directly. When the catalyst is separated from the reaction mixture, the formation of the coupling product stops, indicating that the active $\mathrm{Cu}$ species are those supported on $\mathrm{TiO}_{2}$ and the process is heterogeneous. The linear relationship between the initial reaction rate and amount of $\mathrm{Cu}$ species (shown in Figure S24b) also confirms that small CuOx NPs supported on $\mathrm{TiO}_{2}$ are the active species for the oxidative coupling of alkynes.

As discussed previously, $\mathrm{Cu}$ clusters seem not to be active for the oxidative coupling of phenylacetylene. Theoretical calculations have shown that the activation energy of $\mathrm{O}_{2}$ on Cu clusters is quite high, ${ }^{13}$ which may explain the very low activity of $\mathrm{Cu}$ clusters. In the $\mathrm{CuOx} / \mathrm{TiO}_{2}-0.25 \%$ catalyst, $\mathrm{Cu}$ exists as subnanometric species dispersed on $\mathrm{TiO}_{2}$, namely supported $\mathrm{Cu}$ clusters. As can be seen in Figure 5a, $\mathrm{CuOx} / \mathrm{TiO}_{2}-0.25 \%$ sample shows negligible activity and, in any case, the activity per $\mathrm{Cu}$ atom is much lower than that for $\mathrm{CuOx} / \mathrm{TiO}_{2}-2.5 \%$ with $\mathrm{CuOx} \mathrm{NPs}$ around $2 \mathrm{~nm}$. On the other hand, when the size of $\mathrm{CuOx}$ NPs in $\mathrm{CuOx} / \mathrm{TiO}_{2}$ sample is larger than $5 \mathrm{~nm}$, the activity drops dramatically, indicating that only CuOx NPs around $2 \mathrm{~nm}$ are active. It should be taken into account that, due to the stabilization effect of $\mathrm{TiO}_{2}$ support and, specially, to the use of toluene instead of DMSO as solvent, large CuOx NPs ( $\geq 5 \mathrm{~nm})$ cannot undergo in situ transformation into smaller NPs during the oxidative coupling reaction, what results in their low activity. At this point, it has become clear that regardless how the CuOx NPs are obtained, a maximum activity for the oxidative coupling of phenylacetylene occurs with CuOx NPs of $\sim 2 \mathrm{~nm}$. Thus, now we will attempt 
to explain the size-dependent activity of $\mathrm{CuOx}$ NPs for the oxidative coupling of alkynes.

\subsection{Kinetic and in situ spectroscopic studies}

The global process for oxidative coupling of alkynes can be decomposed into the following elementary steps: activation of the $\mathrm{C}-\mathrm{H}$ bond in the alkyne group, coupling reaction, $\mathrm{O}_{2}$ activation and reaction of the adsorbed $\mathrm{H}$ with the activated $\mathrm{O}_{2}{ }^{26}$ To find which one is the reaction controlling step, $\mathrm{CuOx} / \mathrm{TiO}_{2}-2.5 \%$ was used as catalysts and the initial rate of the reaction was measured by keeping the $\mathrm{O}_{2}$ pressure ( 1 bar) constant and changing the initial concentration of phenylacetylene. Results in Figure S25 indicate that under these reaction conditions, the rate of the reaction does not depend on the concentration of alkyne, indicating that neither the phenylacetylene activation nor the homo-coupling can be the rate-controlling step. On the other hand, the initial rate of the reaction clearly increases when increasing the oxygen pressure while keeping the concentration of phenylacetylene constant. From the kinetic results, one should then conclude that the controlling step during the oxidative coupling of alkynes corresponds to $\mathrm{O}_{2}$ activation, or to the reaction between activated $\mathrm{O}_{2}$ and the abstracted hydrogen.

With respect to the molecular interaction of the reactants with the catalyst, the surface interaction of phenylacetylene was clearly seen from the UV-vis spectra of the alkyne adsorbed on the monodispersed CuOx NPs (see Figure S26). When phenylacetylene is interacted with CuOx NPs at room temperature, no obvious change occurs in the UV-vis spectra. However, when the system is heated to the reaction temperature $\left(90^{\circ} \mathrm{C}\right.$ ), a new peak at $\sim 475 \mathrm{~nm}$ is observed that can be associated to the formation of $\mathrm{C} \equiv \mathrm{C}$-Cu bond, suggesting that the adsorption and dissociation of the $\mathrm{C}-\mathrm{H}$ bond of phenylacetylene on the CuOx NPs has occurred. ${ }^{27}$ After one hour, when the phenylacetylene has been consumed, the peak at $\sim 475 \mathrm{~nm}$ disappears.

Alkyne activation on supported CuOx NPs has also been studied by in situ IR spectroscopy. When deuterated phenylacetylene is adsorbed on $\mathrm{TiO}_{2}, \mathrm{CuOx} / \mathrm{TiO}_{2}-2.5 \%$ (active sample) and $\mathrm{CuOx} / \mathrm{TiO}_{2}-10 \%$ (non-active sample), a band corresponding to O-D bond has been identified in all samples at room temperature (see Figure S27). It was not possible to identify whether the -OD groups come from the $\mathrm{TiO}_{2}$ support or from the $\mathrm{CuO}_{\mathrm{X}} \mathrm{NP}$, due to the fact that a fast isotopic scrambling with the -OH groups of the support can also occur. On the other hand, the formation of $\mathrm{C} \equiv \mathrm{C}-\mathrm{Cu}$ bond 
at the surface is consistent with the presence of a rather asymmetric $\mathrm{C} \equiv \mathrm{C}$ IR bond in both $\mathrm{CuOx} / \mathrm{TiO}_{2}$ samples (see Figure S28) when compared with that formed on pure $\mathrm{TiO}_{2}$. The asymmetric vibration mode of $\mathrm{C} \equiv \mathrm{C}$ bond in IR spectra can be due to the interaction of the $\mathrm{Ph}-\mathrm{C} \equiv \mathrm{C}$-* adduct with surface copper sites on both $\mathrm{CuOx} / \mathrm{TiO}_{2}-2.5 \%$ and $\mathrm{CuOx} / \mathrm{TiO}_{2}-10 \%{ }^{28}$ According to the data from UV-vis and IR spectra, $\mathrm{C} \equiv \mathrm{C}-\mathrm{H}$ activation really occur on the surface of the $\mathrm{CuOx}$ nanoparticles.

XPS results of $\mathrm{CuOx} / \mathrm{TiO}_{2}-2.5 \%$ and $\mathrm{CuOx} / \mathrm{TiO}_{2}-10 \%$ presented before showed that the chemical states of $\mathrm{Cu}$ species in the two samples are different, which may be a reason for their different catalytic activity. To further investigate the nature of the surface $\mathrm{Cu}$ species on $\mathrm{CuOx} / \mathrm{TiO}_{2}-2.5 \%$ and $\mathrm{CuOx} / \mathrm{TiO}_{2}-10 \%$ in the presence of phenylacetylene and $\mathrm{O}_{2}$, $\mathrm{CO}$ has been used as probe molecule for in situ IR spectroscopy. Indeed, $\mathrm{CO}$ is very sensitive to $\mathrm{Cu}(\mathrm{I})$ species while $\mathrm{Cu}(\mathrm{II})$ cannot be detected by CO even at low temperature. ${ }^{29,30}$ As depicted in Figure S29, Cu(I) has been observed on both samples after the adsorption of phenylacetylene at $90{ }^{\circ} \mathrm{C}$ for 1 hour due to the surface reduction reaction. After $\mathrm{O}_{2}$ addition at $90{ }^{\circ} \mathrm{C}$, interestingly, the amount of $\mathrm{Cu}(\mathrm{I})$ remains stable on the $\mathrm{CuOx} / \mathrm{TiO}_{2}-2.5 \%$ sample while the amount of $\mathrm{Cu}(\mathrm{I})$ clearly decreases on $\mathrm{CuOx} / \mathrm{TiO}_{2}-10 \%$ sample as a result of re-oxidation of $\mathrm{Cu}(\mathrm{I})$ into $\mathrm{Cu}(\mathrm{II})$ by $\mathrm{O}_{2}$. In other words, these results indicate that the type of interaction between $\mathrm{O}_{2}$ and the $\mathrm{CuOx}$ NPs and the nature of the active oxygen species are different in the two samples. Therefore, since the rate-controlling step in the oxidative coupling of alkynes is $\mathrm{O}_{2}$ activation, the observed size effects of $\mathrm{CuOx}$ NPs on the catalytic properties for oxidative coupling of alkynes should be related to their influence on the activation of $\mathrm{O}_{2}$. 


\subsection{Relation between particle size of $\mathrm{CuOx}$ and $\mathrm{O}_{2}$ activation}
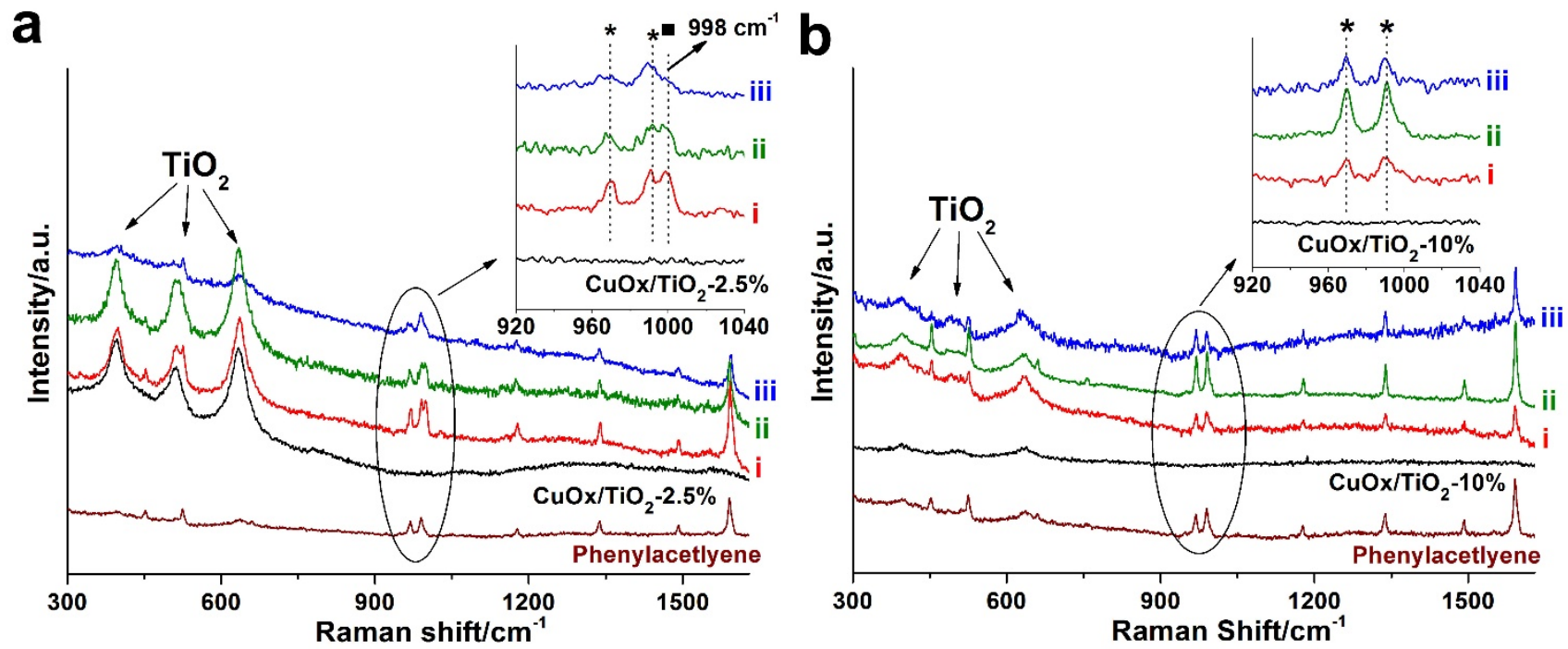

Figure 6 In situ Raman spectra of $\mathrm{CuOx} / \mathrm{TiO}_{2}-2.5 \%$ (a) and $\mathrm{CuOx} / \mathrm{TiO}_{2}-10 \%$ (b) in $\mathrm{O}_{2}$ atmosphere after pre-treatments in reactant mixture of phenylacetylene and $\mathrm{O}_{2}$. In (a) and (b), spectra were obtained at different temperature. (i) $25{ }^{\circ} \mathrm{C}$, (ii) $60{ }^{\circ} \mathrm{C}$ and (iii) $90{ }^{\circ} \mathrm{C}$. For comparison, the fresh $\mathrm{CuOx} / \mathrm{TiO}_{2}$ samples and phenylacetylene adsorbed on $\mathrm{CuOx} / \mathrm{TiO}_{2}$ are also presented.

To further identify the nature of surface species generated under reaction conditions, in situ Raman and in situ IR studies have been performed on both $\mathrm{CuOx} / \mathrm{TiO}_{2}-2.5 \%$ and $\mathrm{CuOx} / \mathrm{TiO}_{2}-10 \%$ samples. Figure 6a shows the in situ Raman spectra acquired on the active $\mathrm{CuOx} / \mathrm{TiO}_{2}-2.5 \%$ sample in the presence of phenylacetylene and $\mathrm{O}_{2}$ at different reaction temperatures. A Raman band at $998 \mathrm{~cm}^{-1}$, ascribed to peroxo species, is clearly detected at $25^{\circ} \mathrm{C}, 60{ }^{\circ} \mathrm{C}$ and at the reaction temperature used in the catalytic studies $\left(90{ }^{\circ} \mathrm{C}\right) .{ }^{31}$ No peroxo species have been detected on pure $\mathrm{TiO}_{2}$. Notice that a decrease in the intensity of the $998 \mathrm{~cm}^{-1}$ band at $90{ }^{\circ} \mathrm{C}$ occurs, which could be due to thermal desorption or to dissociation into atomic oxygen, and regeneration of surface lattice oxygen species. Moreover, peroxo species (IR active vibration mode at 1227 and $1217 \mathrm{~cm}^{-1}$ ) have also been detected by in situ IR studies performed at different reaction temperatures (Figure S30a). ${ }^{32}$ These results indicate that peroxo species can be formed on the surface of $\mathrm{CuOx} / \mathrm{TiO}_{2}-2.5$ sample. In opposite, on the much less active $\mathrm{CuOx} / \mathrm{TiO}_{2}-10 \%$ sample, peroxo species have not been observed during the in situ Raman studies (Figure 6b), and peroxo species (1227 and $1217 \mathrm{~cm}^{-1}$ ) are detected by IR spectroscopy only at $25{ }^{\circ} \mathrm{C}$ and disappear after increasing temperatures to $60{ }^{\circ} \mathrm{C}$ (Figure S30b). 
Based on these data, it can be speculated that oxygen as peroxo species is preferentially stabilized on the $\mathrm{CuO}_{\mathrm{X}} / \mathrm{TiO}_{2}-2.5 \%$ sample. In contrast, the peroxo species and less favorable on $\mathrm{CuOx} / \mathrm{TiO}_{2}-10 \%$ at the reaction temperature. Considering the high reactivity of peroxo species in selective oxidation reaction, the formation of peroxo species could be the reason accounting for the higher activity of $\mathrm{CuOx} / \mathrm{TiO}_{2}-2.5 \%{ }^{33}$
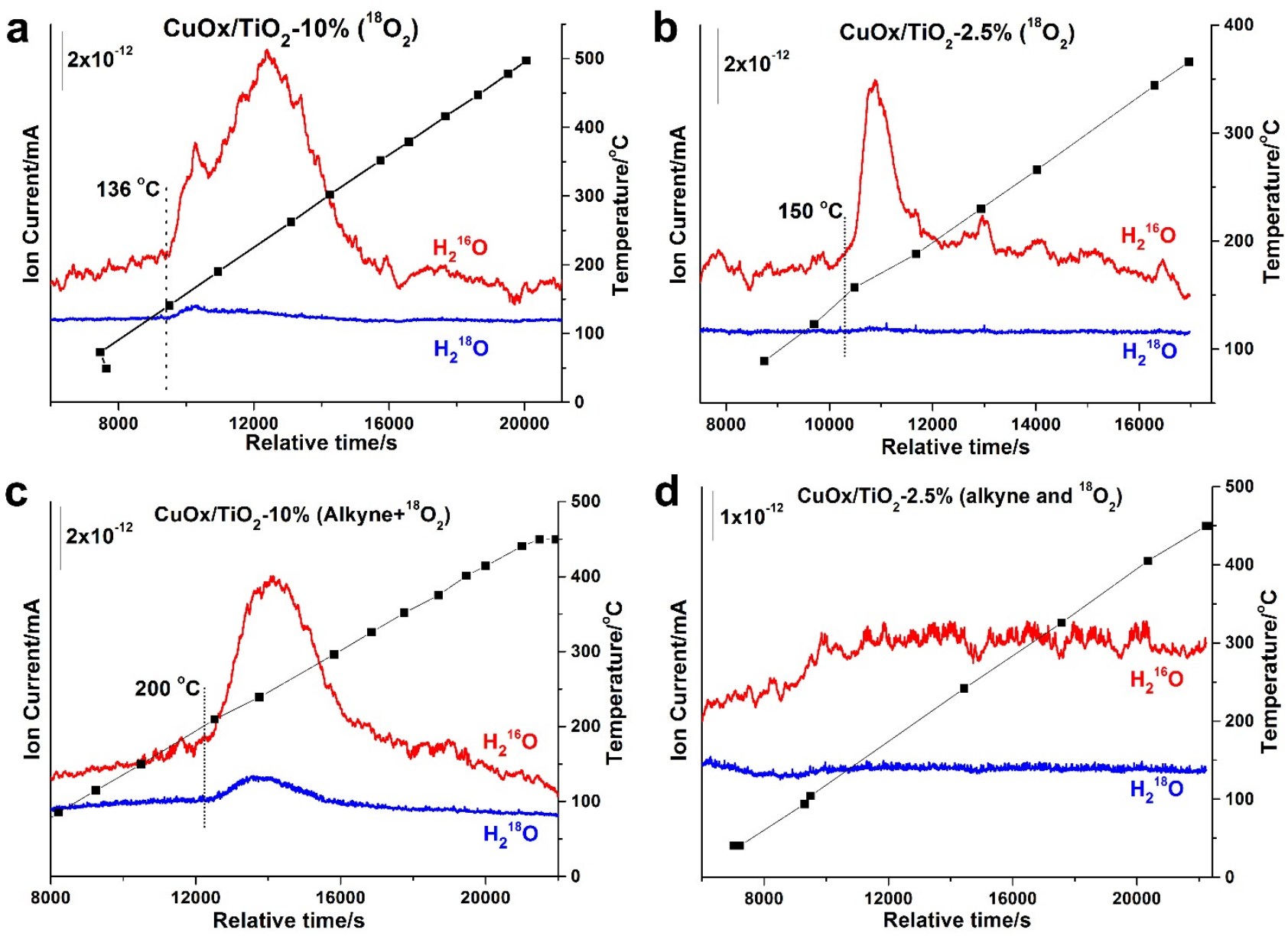

Figure 7 TPR profile on ${ }^{18} \mathrm{O}_{2}$ oxidized $\mathrm{CuO}_{\mathrm{X}} / \mathrm{TiO}_{2}-10 \%$ and $\mathrm{CuO}_{\mathrm{X}} / \mathrm{TiO}_{2}-2.5 \%$ samples (a, b), and after in situ reaction in the presence of phenylacetlyene and ${ }^{18} \mathrm{O}_{2}$ (c, d).

It has been presented in the literature that oxygen activation can also be performed with the help of surface lattice defects. ${ }^{34}$ Since we cannot observe surface adsorbed active oxygen species on $\mathrm{CuOx} / \mathrm{TiO}_{2}-10 \%$, the activation of $\mathrm{O}_{2}$ on $\mathrm{CuOx} / \mathrm{TiO}_{2}-10 \%$ may be performed through the re-oxidation of $\mathrm{Cu}(\mathrm{I})$ species on big $\mathrm{CuOx}$ NPs as observed in the IR spectra (see Figure S29). In order to distinguish whether the different reactivity is associated to peroxo species or lattice oxygen species, ${ }^{18} \mathrm{O}_{2}$ has been used for the in situ spectroscopic studies. By analyzing the composition of 
water $\left(\mathrm{H}_{2}{ }^{16} \mathrm{O}\right.$ or $\left.\mathrm{H}_{2}{ }^{18} \mathrm{O}\right)$ formed after reaction by $\mathrm{H}_{2}$ titration of the catalyst (TPR), it could be distinguished whether the $\mathrm{O}$ in the water comes from the ${ }^{18} \mathrm{O}_{2}$ feed or from the lattice oxygen of $\mathrm{CuOx} / \mathrm{TiO}_{2}$ catalyst (the corresponding TPR profile are shown in Figure 7). For comparison, the fresh $\mathrm{CuOx} / \mathrm{TiO}_{2}-2.5 \%$ and $\mathrm{CuOx} / \mathrm{TiO}_{2}-10 \%$ were oxidized by ${ }^{18} \mathrm{O}_{2}$ at $90{ }^{\circ} \mathrm{C}$ and then reduced by $\mathrm{H}_{2}$. The TPR profile of the ${ }^{18} \mathrm{O}_{2}$ oxidized $\mathrm{CuOx} / \mathrm{TiO}_{2}-10 \%$ sample shows both $\mathrm{H}_{2}{ }^{16} \mathrm{O}$ and $\mathrm{H}_{2}{ }^{18} \mathrm{O}$ formation with an onset temperature of $136{ }^{\circ} \mathrm{C}$ in both cases. $\mathrm{H}_{2}{ }^{16} \mathrm{O}$ formation takes place in a very broad temperature range of $136-355{ }^{\circ} \mathrm{C}$, corresponding to lattice oxygen species of different reactivity. A small amount of $\mathrm{H}_{2}{ }^{18} \mathrm{O}$ is formed, indicating the oxygen exchange between ${ }^{18} \mathrm{O} 2$ and the $\mathrm{CuOx}$ NPs in $\mathrm{CuOx} / \mathrm{TiO}_{2}-10 \%$ (see Figure 7a). In opposite the TPR profile of the ${ }^{18} \mathrm{O}_{2}$ oxidized $\mathrm{CuOx} / \mathrm{TiO}_{2}-2.5 \%$ sample, shows only one peak corresponding to $\mathrm{H}_{2}{ }^{16} \mathrm{O}$ with an onset temperature of $150{ }^{\circ} \mathrm{C}$, corresponding to lattice oxygen species. Interestingly $\mathrm{H}_{2}{ }^{18} \mathrm{O}$ is not detected in this sample, indicating that no oxygen exchange between the $\mathrm{O}_{2}$ and the $\mathrm{CuOx}$ lattice takes place on $\mathrm{CuOx} / \mathrm{TiO}_{2}-2.5 \%$ (Figure 7b).

When the two samples have been exposed to a mixture of phenylacetylene and ${ }^{18} \mathrm{O}_{2}$ at reaction conditions (90 ${ }^{\circ} \mathrm{C}, 1 \mathrm{~h}$ ), different TPR profiles have been observed in both cases. On the $\mathrm{CuOx} / \mathrm{TiO}_{2}-2.5 \%$ sample, neither $\mathrm{H}_{2}{ }^{16} \mathrm{O}$ nor $\mathrm{H}_{2}{ }^{18} \mathrm{O}$ are detected (see Figure $7 \mathrm{~d}$ ). It means, the surface has been reduced under reaction conditions, but it is not re-oxidized by ${ }^{18} \mathrm{O}_{2}$. With $\mathrm{CuOx} / \mathrm{TiO}_{2}-10 \%$ sample, both $\mathrm{H}_{2}{ }^{16} \mathrm{O}$ and $\mathrm{H}_{2}{ }^{18} \mathrm{O}$ are observed with an onset temperature of $203{ }^{\circ} \mathrm{C}$ (Figure 7c), which indicates the surface has been partially reduced and re-oxidized by ${ }^{18} \mathrm{O}_{2}$ under reaction conditions.

From the above presented results combined with the in situ Raman and IR studies, we speculate that oxygen is activated by $\mathrm{CuOx}$ NPs in the $\mathrm{CuOx} / \mathrm{TiO}_{2}-2.5 \%$ sample as peroxo species on the catalyst surface. Meanwhile, in the case of $\mathrm{CuOx} / \mathrm{TiO}_{2}-10 \%$ sample, $\mathrm{O}_{2}$ dissociation occurs, transforming into lattice oxygen species. This hypothesis would also be supported by the IR results where the catalysts surface has been titrated, using $\mathrm{CO}$ as probe molecule, after phenylacetylene adsorption at $90{ }^{\circ} \mathrm{C}$ and after subsequent $\mathrm{O}_{2}$ insertion at the same temperature (see Figure S29).

Thus we can conclude that the different reactivity observed between the $\mathrm{CuOx} / \mathrm{TiO}_{2}-2.5 \%$ and $\mathrm{CuOx} / \mathrm{TiO}_{2}-10 \%$ samples is related to a different nature of the oxygen species on the catalyst surface. Stabilization of molecular oxygen as peroxo species or further dissociation into atomic oxygen and 
generation of lattice oxygen species is strongly related to the different particle size of CuOx NP in both samples. On CuOx NPs around $2 \mathrm{~nm}, \mathrm{O}_{2}$ molecules are activated to form peroxo species, which is more active than surface lattice oxygen formed on big $\mathrm{CuOx}$ NPs in $\mathrm{CuOx} / \mathrm{TiO}_{2}-10 \%{ }^{35,36}$ As a consequence, $\mathrm{CuOx} / \mathrm{TiO}_{2}-2.5 \%$ with $\sim 2 \mathrm{~nm}$ particle size shows much higher activity than $\mathrm{CuOx} / \mathrm{TiO}_{2}-10 \%$ with $\sim 10 \mathrm{~nm}$ particle size in the oxidative coupling of alkynes. Notice that this is the case regardless that monodispersed isolated CuOx NPs or supported NPs are used as catalysts. 


\subsection{Proposed reaction mechanism}
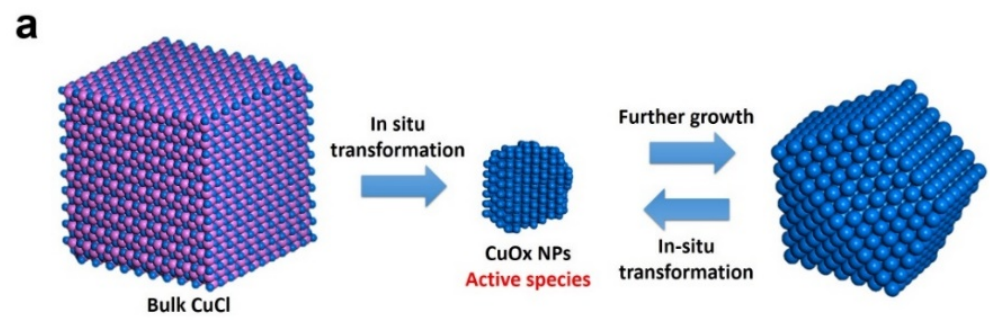

b

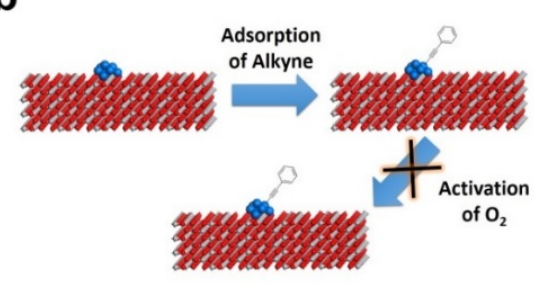

C

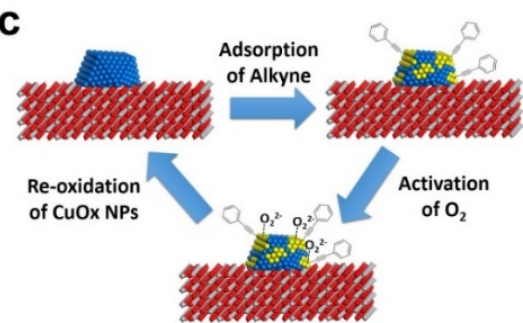

d

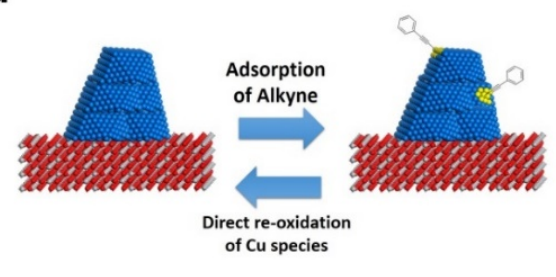

Figure 8 (a) Schematic illustration of the dynamic transformation of monodispersed Cu species. Size-dependent catalytic mechanism of supported $\mathrm{CuOx}$ NPs, (b) $\mathrm{CuOx} / \mathrm{TiO}_{2}-0.25 \%$, (c) $\mathrm{CuOx} / \mathrm{TiO}_{2}-2.5 \%$ and (d) $\mathrm{CuOx} / \mathrm{TiO}_{2}-10 \%$.

Based on the above results and discussions, a proposed reaction mechanism for CuOx NPs with different sizes is shown in Figure 8. For monodispersed $\mathrm{Cu}$ species (see Figure 8a), small CuOx NPs around $2 \mathrm{~nm}$ are formed from the in situ transformation of bulk $\mathrm{CuCl}$, as a result of which an induction period can be observed. These in situ formed small CuOx NPs are the active species for the oxidative coupling of alkynes when DMSO was chosen as solvent. When a large amount of $\mathrm{CuCl}$ is used as the catalyst, small CuOx NPs will further grow into big CuOx NPs around 5 nm, which can transform back with time to small $\mathrm{CuOx}$ NPs in the oxidative coupling of alkynes. In the case of supported $\mathrm{CuOx}$ NPs (see Figure $\mathbf{8 b}$ to Figure 8d), the activity will also be dependent on the size of $\mathrm{CuOx}$ NPs, being the dynamic transformation between different sizes of CuOx NPs restricted under the reaction condition used here. For $\mathrm{Cu}$ clusters supported on $\mathrm{TiO}_{2}$, according to theoretical calculation, $\mathrm{O}_{2}$ activation is not favorable, resulting in their very low activity. When the size of $\mathrm{CuOx}$ NPs increases to around $2 \mathrm{~nm}, \mathrm{O}_{2}$ can be activated into active peroxo species on the surface of $\mathrm{CuOx} / \mathrm{TiO}_{2}-2.5 \%$, which can serve as the active intermediate for the oxidative coupling of alkynes. However, a further increase in the size of $\mathrm{CuOx}$ NPs will change the nature of the oxygen species formed. $\mathrm{O}_{2}$ will form lattice oxygen species after activation by large $\mathrm{CuOx}$ NPs, which is less active 
for the oxidative coupling reaction.

\subsection{Synthesis of unsymmetric 1,3-diynes with $\mathrm{CuOx} / \mathrm{TiO}_{2}$ catalyst}

Compared with oxidative homo-coupling of alkynes, the coupling reaction between two different alkyne molecules is more difficult due to their different reactivity. The yield of unsymmetric 1,3-diynes is much lower than the oxidative homo-coupling of alkynes as a result of the competitive reaction pathways between homo-coupling and hetero-coupling reactions. ${ }^{37}$ Therefore, in some cases, only trace amount of 1,3-diynes can be obtained when Cu-based catalyst is used, even though one alkyne substrate is in a large excess (the molar ratio of two alkynes is 5.). ${ }^{38,39}$ Since the CuOx NPs supported $\mathrm{TiO}_{2}$ in the $\mathrm{CuOx} / \mathrm{TiO}_{2}-2.5 \%$ sample can catalyze the oxidative coupling of alkynes directly, the oxidative hetero-coupling of different alkynes could be processed smoothly with higher yield of unsymmetric 1,3-diynes. The catalytic results in the synthesis of unsymmetric 1,3-diynes with $\mathrm{CuOx} / \mathrm{TiO}_{2}$ catalyst are shown in Table 2. It should be noted that, in this work, the molar ratio of two alkynes is 2 . And higher temperature and $\mathrm{O}_{2}$ pressure is used to accelerate the hetero-coupling between different alkynes. As can be seen in Table 2, unsymmetric 1,3-diynes can be obtained with moderate to good yield, ranging from $61 \%$ to $92 \%$. The coupling between phenylacetylene and hexyne can be realized with $61 \%$ yield although the amount of phenylacetylene is only twice that of hexyne. It should be noticed that only trace amount of the unsymmetric coupling product was obtained in previous work (but five times excess of hexyne). ${ }^{40}$ These results suggest that supported small $\mathrm{CuOx}$ NPs can work as efficient catalyst for synthesis of unsymmetric 1,3-diynes.

Table 2. Synthesis of unsymmetric 1,3-diynes with $\mathrm{CuOx} / \mathrm{TiO}_{2}$ catalyst ${ }^{\mathrm{a}}$

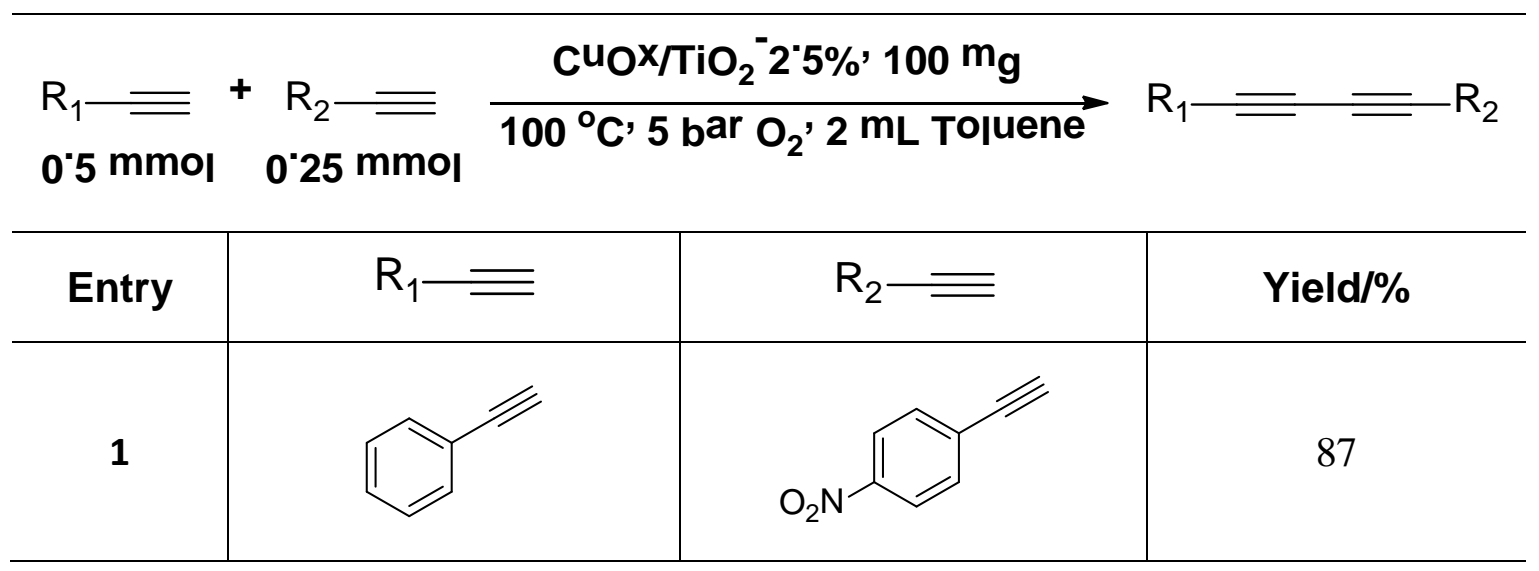




\begin{tabular}{l|l|l|l|}
\hline & \\
\hline 5 &
\end{tabular}

a $40 \mu \mathrm{L}$ dodecane was added as internal standard and the reaction time was $8 \mathrm{~h}$. The yield is calculated based on $\mathrm{R}_{2} \bar{\equiv}$.

\section{Conclusions}

In this work, a facile method for synthesis of monodispersed small CuOx NPs has been presented. Through kinetic analysis and following the dynamic transformation of $\mathrm{Cu}$ species, small CuOx NPs around $2 \mathrm{~nm}$ are proved to be the active species in Cu-catalyzed oxidative coupling of alkynes. Furthermore, the size-dependent catalytic properties of supported $\mathrm{CuOx} \mathrm{NPs}$ on $\mathrm{TiO}_{2}$ was also studied. Similar activity trend is obtained on supported CuOx NPs and monodispersed CuOx NPs. By spectroscopic characterizations, it has been clarified that the nature of the active oxygen species are dependent on the size of CuOx NPs. Active peroxo species are preferentially formed on small $\mathrm{CuOx}$ NPs $(\sim 2 \mathrm{~nm})$ while $\mathrm{O}_{2}$ prefers to form lattice oxygen species after dissociation on large $\mathrm{CuOx}$ 
NPs $(\sim 10 \mathrm{~nm})$. Therefore, the catalytic properties in oxidative coupling of alkynes are greatly dependent on the size of CuOx. Finally, monodispersed CuOx NPs are able to catalyze the unsymmetric coupling of alkynes.

\section{ASSOCIATED CONTENT}

\section{Supporting Information}

This material is available free of charge via the Internet at http://pubs.acs.org.

\section{AUTHOR INFORMATION}

*Corresponding author: acorma@itq.upv.es (A.C.)

Notes

The authors declare no competing financial interests.

\section{ACKNOWLEDGEMENT}

L. L. thanks ITQ for providing a contract. The authors also thank Microscopy Service of UVP for kind help on TEM and STEM measurements. Financial supports from Consolider-Ingenio 2010 (project MULTICAT) and “Severo Ochoa” program are also gratefully acknowledged. The European Union is also acknowledged by ERC-AdG-2014-671093 — SynCatMatch.

\section{References}

(1) Kuo, C.-H.; Huang, M. H. Nano Today 2010, 5, 106-116.

(2) Zhang, Q.; Zhang, K.; Xu, D.; Yang, G.; Huang, H.; Nie, F.; Liu, C.; Yang, S. Prog. Mater. Sci. 2014, 60, 208-337.

(3) Yin, M.; Wu, C. K.; Lou, Y.; Burda, C.; Koberstein, J. T.; Zhu, Y.; O'Brien, S. J. Am. Chem. Soc. 2005, 127, 9506-9511.

(4) Hua, Q.; Cao, T.; Gu, X. K.; Lu, J.; Jiang, Z.; Pan, X.; Luo, L.; Li, W. X.; Huang, W. Angew. Chem. Int. Ed. 2014, 53, 4856-4861.

(5) Liu, Y.; Shi, J.; Peng, Q.; Li, Y. Chem. Eur. J. 2013, 19, 4319-4326. 
(6) Allen, S. E.; Walvoord, R. R.; Padilla-Salinas, R.; Kozlowski, M. C. Chem. Rev. 2013, 113, 6234-6458.

(7) Wendlandt, A. E.; Suess, A. M.; Stahl, S. S. Angew. Chem. Int. Ed. 2011, 50, 11062-11087.

(8) Haack, P.; Limberg, C. Angew. Chem. Int. Ed. 2014, 53, 4282-4293.

(9) Zhang, G.; Yi, H.; Zhang, G.; Deng, Y.; Bai, R.; Zhang, H.; Miller, J. T.; Kropf, A. J.; Bunel, E. E.; Lei, A. J. Am. Chem. Soc. 2014, 136, 924-926.

(10) Oliver-Messeguer, J.; Liu, L.; Garcia-Garcia, S.; Canos-Gimenez, C.; Dominguez, I.; Gavara, R.; Domenech-Carbo, A.; Concepcion, P.; Leyva-Perez, A.; Corma, A. J. Am. Chem. Soc. 2015, 137, 3894-3900.

(11) Chen, P.; Solomon, E. I. Proc. Natl. Acad. Sci. USA 2004, 101, 13105-13110.

(12) Solomon, E. I.; Chen, P.; Metz, M.; Lee, S.-K.; Palmer, A. E. Angew. Chem. Int. Ed. 2001, 40, 4570-4590.

(13) Fernández, E.; Boronat, M.; Corma, A. J. Phys. Chem. C 2015, 119, 19832-19846.

(14) Vilar-Vidal, N.; Rivas, J.; López-Quintela, M. A. ACS Catal. 2012, 2, 1693-1697.

(15) Zou, W.; Liu, L.; Zhang, L.; Li, L.; Cao, Y.; Wang, X.; Tang, C.; Gao, F.; Dong, L. Appl. Catal. A: Gen. 2015, 505, 334-343.

(16) Bao, H.; Zhang, W.; Hua, Q.; Jiang, Z.; Yang, J.; Huang, W. Angew. Chem. Int. Ed. 2011, 50, 12294-12298.

(17) Göbel, A.; Ruf, T.; Cardona, M.; Lin, C. T. Phys. B: Conden. Matter. 1996, 219-220, 511-513.

(18) Kliche, G.; Popovic, Z. V. Phys. Rew. B., 1990, 42, 10060-10066.

(19) Xu, J. F.; Ji, W.; Shen, Z. X.; Li, W. S.; Tang, S. H.; Ye, X. R.; Jia, D. Z.; Xin, X. Q. J. Raman Spectrosc. 1999, 30, 413-415

(20) Strohmeier, B. R.; Leyden, D. E.; Field, R. S.; Hercules, D. M. J. Catal., 1985, 94, 514-530.

(21) Vilar-Vidal, N.; Blanco, M. C.; López-Quintela, M. A.; Rivas, J.; Serra, C. J. Phys. Chem. C, 2010, 114, 15924-15930.

(22) Grünert, W.; Hayes, N.W.; Joyner, R.W.; Shpiro, E.S.; Rafiq, M.; Siddiqui, H.; Baeva, G. J. Phys. Chem., 1994, 98, 10832-10846.

(23) Adimurthy, S., Malakar, C. C., Beifuss, U. J. Org. Chem., 2009, 74, 5648-5651.

(24) Oishi, T., Katayama, T., Yamaguchi, K., Mizuno, N. Chem. Eur. J., 2009, 15, 7539-7542. 
(25) Chary, K. V.; Sagar, G. V.; Naresh, D.; Seela, K. K.; Sridhar, B. J. Phys. Chem. B 2005, 109, 9437-9444.

(26) Fomina, L.; Vazquez, B.; Tkatchouk, E.; Fomine, S. Tetrahedron 2002, 58, 6741-6747.

(27) Sagadevan, A.; Ragupathi, A.; Lin, C.-C.; Hwu, J. R.; Hwang, K. C. Green Chem. 2015, 17, 1113-1119.

(28) Maity, P.; Takano, S.; Yamazoe, S.; Wakabayashi, T.; Tsukuda, T. J. Am. Chem. Soc. 2013, 135, 9450-9457.

(29) Hadjiivanov, K. I.; Kantcheva, M. M.; Klissurski, D. G. J. Chem. Soc., Faraday Trans., 1996, 92, 4595-4600.

(30) Kannan, S.; Venkov, T.; Hadjiivanov, K.; Knözinger, H. Langmuir, 2004, 20, 730-736.

(31) Guzman, J.; Carrettin, S.; Corma, A. J. Am. Chem. Soc. 2005, 127, 3286-3287.

(32) Root, D. E.; Mahroof-Tahir, M.; Karlin, K. D.; Solomon, E. I. Inorg. Chem. 1998, 37, 4838-4848.

(33) Metal-Oxo and Metal-Peroxo Species in Catalytic Oxidations; Meunier, B., Ed.; Springer: Berlin Heidelberg, 2000; p 179-211.

(34) Palmer, M. S.; Neurock, M.; Olken, M. M. J. Am. Chem. Soc. 2002, 124, 8452-8461.

(35) Wu, Z.; Li, M.; Howe, J.; Meyer, H. M., III; Overbury, S. H. Langmuir 2010, 26, 16595-16605.

(36) Huang, M.; Fabris, S. Phys. Rev. B 2007, 75, 081404.

(37) Peng, H.; Xi, Y.; Ronaghi, N.; Dong, B.; Akhmedov, N. G.; Shi, X. J. Am. Chem. Soc. 2014, 136, 13174-13177.

(38) Yin, W.; He, C.; Chen, M.; Zhang, H.; Lei, A. Org. Lett. 2009, 11, 709-712.

(39) Siemsen, P.; Livingston, R. C.; Diederich, F. Angew. Chem. Int. Ed. 2000, 39, 2632-2657.

(40) Wang, D.; Li, J.; Li, N.; Gao, T.; Hou, S.; Chen, B. Green Chem. 2010, 12, 45-48. 
TOC image

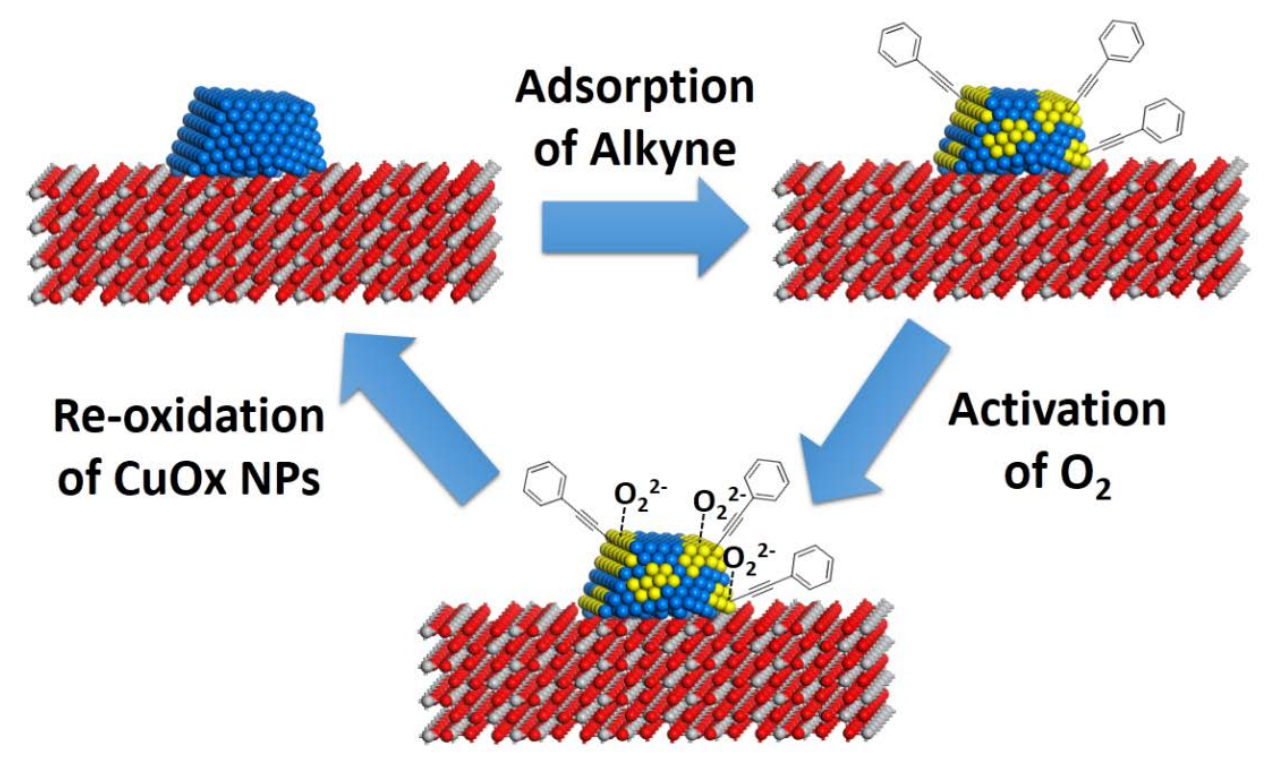

